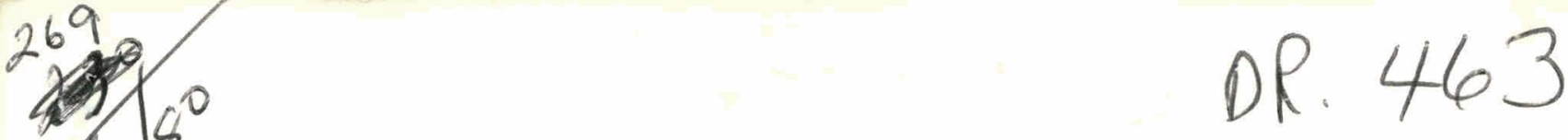

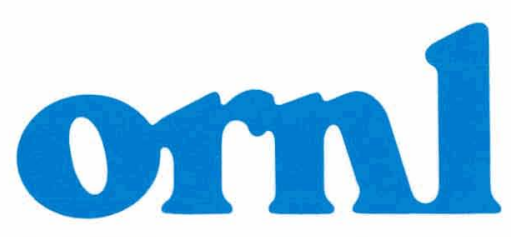

OAK

RIDGE

NATIONAL

LABORATORY

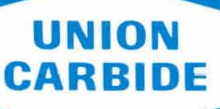

\title{
Nondestructive Inspection of Plasma-Sprayed Metallic Coatings for Coal Conversion Equipment
}
G. W. Scott
S. D. Snyder
W. A. Simpson, Jr. 


\section{DISCLAIMER}

This report was prepared as an account of work sponsored by an agency of the United States Government. Neither the United States Government nor any agency Thereof, nor any of their employees, makes any warranty, express or implied, or assumes any legal liability or responsibility for the accuracy, completeness, or usefulness of any information, apparatus, product, or process disclosed, or represents that its use would not infringe privately owned rights. Reference herein to any specific commercial product, process, or service by trade name, trademark, manufacturer, or otherwise does not necessarily constitute or imply its endorsement, recommendation, or favoring by the United States Government or any agency thereof. The views and opinions of authors expressed herein do not necessarily state or reflect those of the United States Government or any agency thereof. 


\section{DISCLAIMER}

Portions of this document may be illegible in electronic image products. Images are produced from the best available original document. 
Printed in the United States of America. Available from National Technical Information Service

U.S. Department of Commerce

5285 Port Royal Road, Springfield, Virginia 22161

NTIS price codes-Printed Copy: A04 Microfiche A01

This report was prepared as an account of work sponsored by an agency of the United States Government. Neither the United States nor any agency thereof, nor any of their employees, makes any warranty, expressed or implied, or assumes any legal liability or responsibility for any third party's use or the results of such use of any information, apparatus, product or process disclosed in this report, or represents that its use by such third party would not infringe privately owned rights. 
ORNL/TM-7090

Distribution

Categories UC-90c, $-h$

Contract No. W-7405-eng-26

METALS AND CERAMICS DIVISION

NONDESTRUCTIVE INSPECTION OF PLASMA-SPRAYED METALLIC COATINGS FOR

COAL CONVERSION EQUIPMENT

G. W. Scott, S. D. Snyder, and W. A. Simpson, Jr.

Date Published: December 1979

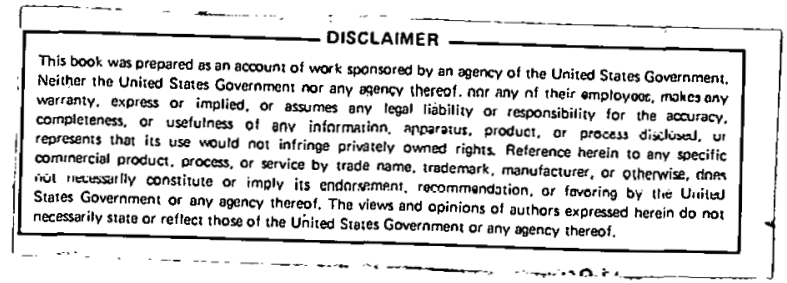

NOTICE This document contains information of a prellminary hature. It is subject to revision or correction and therefore does not represent a final report.

OAK RIUGE NATIONAL LABORATORY

Oak Ridge, Tennessee 37830 operated by

UNION CARBIDE CORPORATION

for the

DEPARTMENT OF ENERGY 


\section{THIS PAGE}

WAS INTENTIONALLY

LEFT BLANK 
CONTENTS

ABSTRACT . . . . . . . . . . . . . . . . . . . 1

INTRODUCTION . . . . . . . . . . . . . . . . . . . 1

MATERIALS AND SPECIMENS .................. 2

LIQUID-PENETRANT TESTING . . . . . . . . . . . . . . 9

Experimental Work . . . . . . . . . . . . . . 9

Discussion ...................... 11

Conclusions . . . . . . . . . . . . . . . 12

RADIOGRAPHY . . . . . . . . . . . . . . . . . 12

Theory ....................... 13

Material Difference Between the Coating

and Substrate .............. 13

Porosity in the Coating Material . . . . . . . 15

Factors Affecting Definition . . . . . . . . 16

The Effect of Unsharpness on Contrast . . . . . . . 17

Experimental Work . . . . . . . . . . . . . 18

Other Radiography . . . . . . . . . . . . 21

Conclustons ................ 23

X-RAY FLUORESCENCE TESTING . . . . . . . . . . . . 23

Theory . . . . . . . . . . . . . . . 24

Fluorescence from Mixtures . . . . . . . . . 24

Fluorescence from Layers . . . . . . . . . . . 25

Energy and Emission Analysis of the CoCrAlY Coating

Alloy 800 Subetrate System . . . . . . . . . . 26

Experimental Work..................... 28

Calibration .............. . . 28

Sensitivity. Tests ............. . . 29

Discussion . . . . . . . . . . . . . . . 30

Conclusions . . . . . . . . . . . . . . 30

EDDY-CURRENT METHODS . . . . . . . . . . . . . . . 30

Multiparameter Tests ................. 33

Single-Frequency Test Design . . . . . . . . . . . . 35

Electrical and Magnetic Property Measurements . . . . . . 38 
Simulation of Eddy-Current Instrument Response • • . • 42

Experimental Measurements . . . . . . . . . . . . 45

Property Calculations . • • • • • • • • • • • • 46

Independent Thickness Measurements . . . . . . . . . 47

Results . . . . . . . . . . . . . . . . . . . 47

Discussion . . . . . . . . . . . . . . . . . . . 49

Conclusions . . . . . . . . . . . . . . . . . . . . 50

THERMAL-INSPECTION METHODS • • • • • • • • • • • • • • • • • 50

Theory . . . . . . . . . . . . . . . . . . . 51

Experimental Work. . . . . . . . . . . . . . . . . . . . . 52

Eonglusiono. . . . . . . . . . . . . . . . . . . . 55

CURRENTLY AVAILABLE INSPECTION TECHNOLOGY: SUMMARY

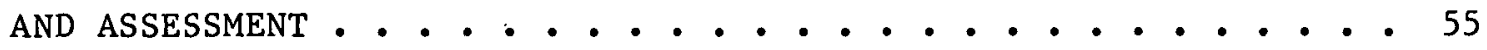

Limitation of Reported Work . . . . . . . . . . . • . : 55

Crack and Hole Detection . . . . . . . . . . . . . . 56

Thickness Measurement . . . . . . . . . . . . . . . 56

Detection of Unbond Areas and Delaminations . . • . • • • . 57

Conclusions and Recommendations . . . . . . . . . . . . 58

ACKNOWLEDGMENTS • • • • • • • • • • • • • • • • • • • • • 58

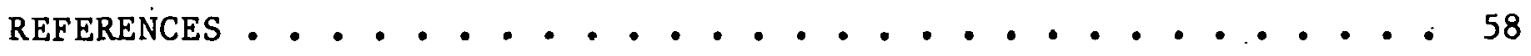


NONDESTRUCTIVE INSPECTION OF PLASMA-SPRAYED METALLIC COATINGS FOR COAL CONVERSION EQUIPMENT

G. W. Scott, S. D. Snyder, * and W. A. Simpson, Jr.

\section{ABSTRACT}

This report describes the results of a project to develop nondestructive inspection techniques for metallic wear- and process-resistant coatings used in coal system components. Physical properties, especially porosity, and the nominal $0.25 \mathrm{~mm}$ (0.010 in.) thickness complicate the inspection of these coatings. The class of coatings selected for laboratory evaluation were CoCrAlY (cobalt-chromium-aluminum-yttrium) types; the specific material used was a Union Carbide spray powder, UCAR LCO-7, which is $\mathrm{Co}-22.8 \% \mathrm{Cr}-12.9 \% \mathrm{Al}-0.6 \% \mathrm{Y}$, sprayed onto alloy 800 substrates.

The desired inspection techniques were to: (1) detect cracks or holes in the coating; (2) measure the coating thickness from the coated side; and ( 3 ) detect lamellar flaws or separations within the coating layer or between the coating and the substrate. Surface methods (such as liquid penetrant), eddy currents, and radiography were investigated for crack and hole detection; eddy currents, $x$-ray fluorescence, and ultrasonics were investigated for thickness measurement; and ultrasonics and infrared thermography were investigated for lamellar flaw detection.

In general, we determined that significant development effort was required to adapt even the more common and highly developed techniques to the coating inspection problems. Significant progress was made in a number of the investigations undertaken, but financial restraints prevented completion of the planned work.

\section{INTRODUCTION}

In January 1976, the ORNL Nondestructive Testing Group began work on a project, Inspection Techniques for Wear- and Process-Resistant Coatings, sponsored by the Materials and Power Generation Branch under the Assistant Administrator for Fossil Energy, U.S. Energy Research and

* Now in Engineering Technol.ngy Division. 
Development Administration (now the Department of Energy). The objective of this project was the development of nondestructive methods to inspect coatings applied to components of coal gasification systems. An earlier report ${ }^{1}$ discussed the general inspection problem in detail. During FY 1978, the project scope was narrowed to concentrate on metallic plasma-sprayed coatings. Specifically, for CoCrAlY (cobaltchromium-aluminum-yttrium) alloy coatings we investigated methods that would: (1) detect cracks or holes in the coatings, (2) measure the coating thickness from the coated side (of a workpiece), and ( 3 ) detect lack of bonding (unbonds) between the coating and the substrate.

Plasma-sprayed coatings typically contain porosity, which may coalesce to produce channels that penetrate the coating to the substrate. To seal and densify the CoCrAlY coatings and thus improve their corrosion resistance, they may be sintered, shot-peened, or hotpressed. The project plan was to develop methods applicable first to the as-sprayed coatings and then determine their applicability to further processed coatings.

After reviewing known nondestructive methods for applicability and liklihood of success, we selected for investigation a primay method and two backup methods for each of the inspection requirements listed above. Table 1 itemizes the selected methods.

'The diverse areas of expertise required by the investigation dictated division of the task, as indicated by the section author identifications. Available resources occasionally dictated deviation from strict priority ranking of effort. The two ultrasonic tasks suffered thus, but earlier work ${ }^{1}$ indicates a possible outcome for detection of unbonds. The thermometric and thermographic work was a natural and efficient extension of the earlier work. The electric current work was eliminated by lack of time.

\section{MATERIALS AND SPECIMENS}

Materials selections were Initially based on results from material screening experiments at Argonne. ${ }^{2-5}$ After termination of the program there, alloy 800 was retained for coating substrates as a "typical" 
Table 1. Candidat? Methods for Nondestructive Inspection of CoCrAlY Coatings

Method Selected for Each Inspection Requirement

\begin{tabular}{|c|c|c|c|}
\hline Cholce & $\begin{array}{c}\text { Detection of Craak or Hole } \\
\text { in Coating }\end{array}$ & $\begin{array}{l}\text { One-Side Measurement } \\
\text { of Coating Thickness }\end{array}$ & $\begin{array}{c}\text { Detection of Coating-Substrate } \\
\text { Unbond Flaws }\end{array}$ \\
\hline 1 & $\begin{array}{l}\text { Surface methods: } \\
\text { penetrant }\end{array}$ & Eddy current & Ultrasonics \\
\hline 2 & Eddy current & $\mathrm{x}$-ray fluorescence & Thermometric or thermographic \\
\hline 3 & $\begin{array}{l}\text { Transmission radiograpizy; } \\
\text { film on coating side }\end{array}$ & U1trasonics & $\begin{array}{l}\text { Electric current: four- } \\
\text { point probe }\end{array}$ \\
\hline
\end{tabular}


high-temperature metal that coatings might be used to protect. It has been used for many coal equipment applications.

The CoCralY alloy family of coatings was specificed by the contractor. ${ }^{6}$ Two suppliers of CoCrAlY powder were identified: Alloys Metals, Inc., (AMI) of Troy, Michigan, and the Coating Service of Union Carbide Linde Division. Alloy Metals showed little interest in supplying the relatively small quantities required. The high-aluminum powder was selected for its increased brittleness, on the assumption that tensilecrack specimens (described below) could be made from it more easily.

Tables 2 and 3 list the compositions assumed for specimen mazerials in test or design calculations. These are based on published nominal values or actual analyses, as indicated.

\begin{tabular}{|c|c|}
\hline Element & wt \% \\
\hline $\mathrm{Fe}$ & 45.50 \\
\hline $\mathrm{Ni}$ & 32.00 \\
\hline $\mathrm{Cr}$ & 20.50 \\
\hline Mn & 0.75 \\
\hline Si & 0.35 \\
\hline $\mathrm{Cu}$ & 0.30 \\
\hline $\mathrm{T} 1^{a}$ & 0.30 \\
\hline $\mathrm{A}^{a}$ & 0.30 \\
\hline c & 0.04 \\
\hline$S$ & 0.007 \\
\hline
\end{tabular}


Table 3. Composition of UCAR

LCO-7 CoCralY Alloy Spray

Powder, Lot $13^{a}$

\begin{tabular}{lc}
\hline Element & wt $\%$ \\
\hline Co & 63.7 \\
$\mathrm{Cr}$ & 22.8 \\
$\mathrm{Al}$ & 12.9 \\
$\mathrm{Y}$ & 0.6 \\
\hline \multicolumn{2}{c}{ a Chemical analysis from } \\
Union Carbide Linde Division \\
Coatings Service, courtesy of \\
A. T. Taylor. The computed \\
theoretical density was 7.124 \\
$\mathrm{Mg} / \mathrm{m}^{3}$.
\end{tabular}

Three types of specimens were planned: free-standing layers, for property measurements; controlled-thickness layers, for development of thickness measurement methods; and tensile-crack specimens, developed for surface method studies. ${ }^{7}$ A specimen similar to that shown in Fig. 1 fulfills the first two requirements; the ones shown in Fig. 2 were used for the third.

As the first group of CoCrAlY specimens was sprayed, a black deposit, assumed to be oxide, formed on the exposed surface after each spray pass. Wire brushing removed the deposit, and the spraying continued. We later designed an attachment for the torch head to increase the gas shielding of the specimen surface around the deposition area heated by the torch.

We initially sprayed three large tensile specimens (Fig. 2) and one disk specimen similar to that shown in Fig. 1. The specimen design in 


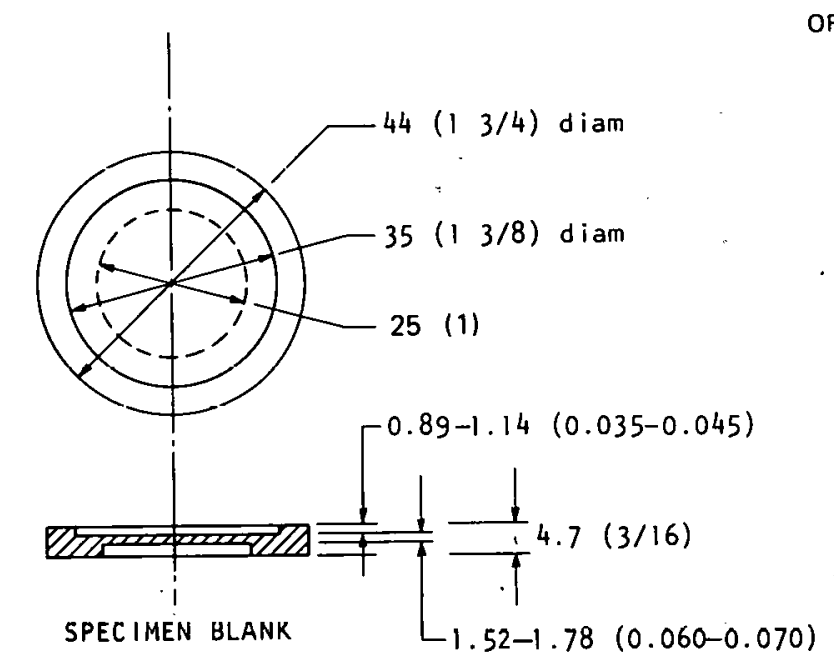

ORNL.DWG 78.9111R

(a)

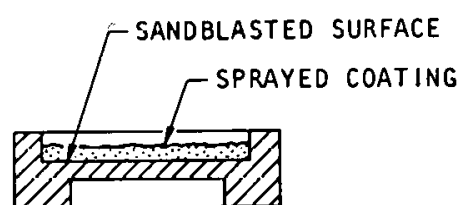

DIMENSIONS IN MILLIMETERS (INCHES)

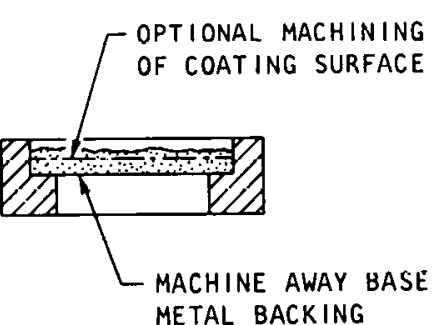

Fig. 1. Steps in Preparing Free-Standing Coating Layer Specimens.

(a)

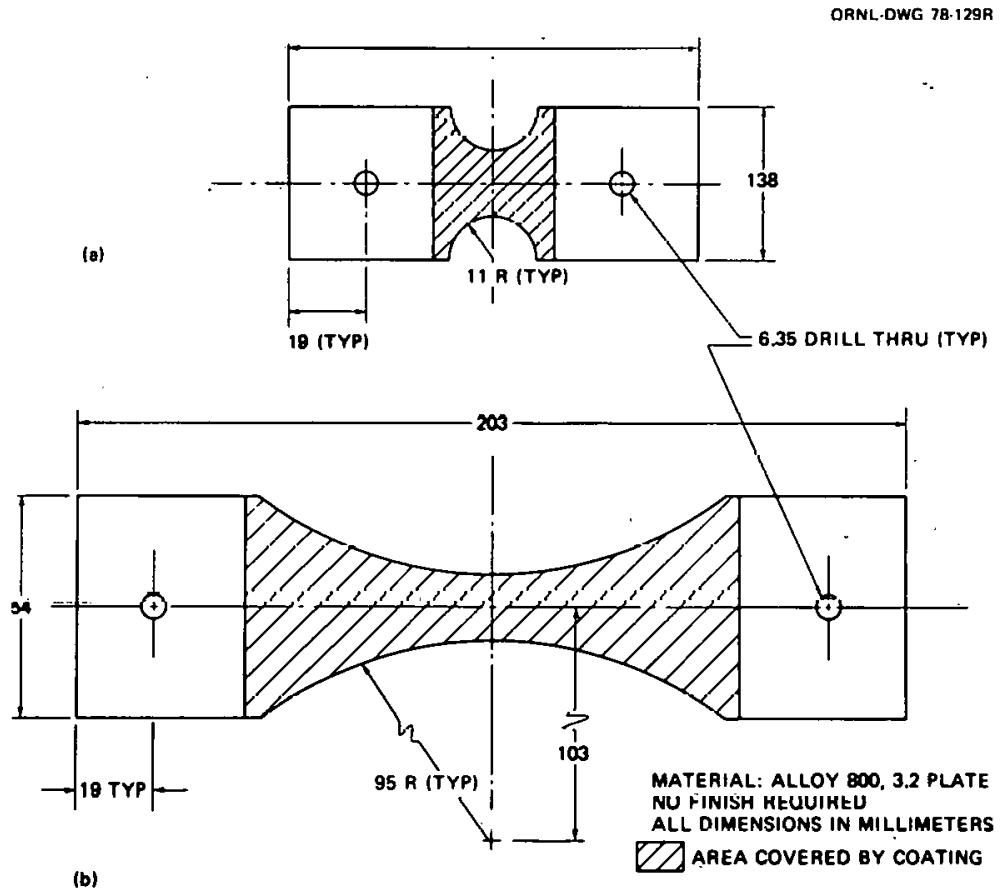

Fig. 2. Tensile-Crack Specimen for Surface Inspection Method Testing. 
Fig. 1 evolved from machining experience with the first disk specimen, described below. The backing material was type 304 stainless steel, sandblasted before coating.

The machining of the first disk specimen (disk 1) resulted in several significant observations. Conventional single-point tools could not machine the oversprayed coating on the uppermost rim; instead, carbide-tipped or diamond tools are required. When the last thin section of backing material was machined loose as a disk and removed, part of the coating in the center was found crumbled (Fig. 3), and none of the coating adhered to the backing. The crumbled volume apparently came from the first spray pass. It did not penetrate the rest of the coating layer. The crumbling was not traceable to machining; the final machining was performed on a jeweler's lathe, and care was taken to avoid both excessive radial chuck pressure and axial tool pressure.

The type of failure observed in this specimen is not among those enumerated in the work statement for this project, although its presence might produce a subsurface defect indication, an unbond indication, or both. Coating specimens in ongoing coal program experiments may develop undetected defects of this type or may have had them before insertion in the experiments.

Additional disk blanks were machined with (nominal) 0.79-, 1.6-, and 3.2-mm (1/32-, 1/16-, and 1/8-in.) backing thicknesses. Our intent was to determine the minimum backing thickness that would tolerate the heat from the spray-coating operation without objectionable deformation. Disk 2 (Fig. 4), with a 1.6-mm backing for the sprayed layer, was coated with CoCrAlY and machined to smooth the oversprayed rim and remove the metal backing.

Although the specimen and manufacturing process were designed with the intent of producing flat coating layers, heating by the spray torch forced the substrate of disk 2 to bow in the center; the coating was thus deposited on a convex substrate. During cooldown, the substrate contracted more than the coating, returning to its original flatness and leaving the coating layer slightly bowed. This difference in contraction also apparently caused the coating and substrate to pull apart, so 

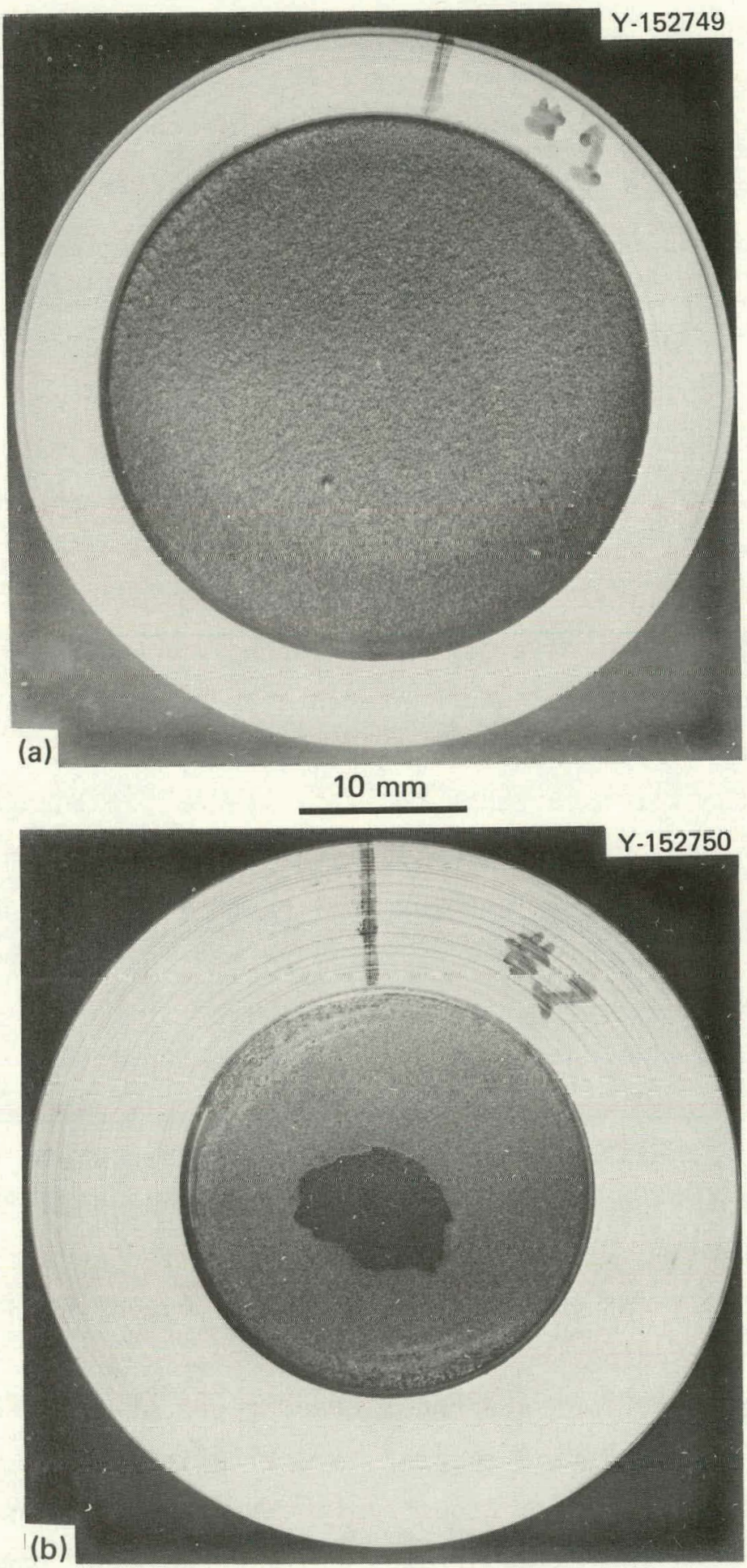

Fig. 3. Disk Specimen 1. (a) Sprayed surface. (b) Back. 
that the coating layer was actually freestanding before the substrate was machined away. The stresses resulting from contraction of the outer (thicker) ring of the substrate apparently caused the coating layer to crack along a segment of its circumference (see Fig. 4).

The lumplike structures on the sprayed surface have not been analyzed; they are assumed to be either powder material or trapped fragments of tungsten electrode material from the spray torch.

\section{LIQUID-PENETRANT TESTING}

S. D. Snyder

As this program advanced, the inspection of thin plasma-sprayed CoCrA1Y intermetallic protective coatings for coal conversion and utilization equipment became of greater interest than the ceramic or cermet coatings previously considered. 8 This change necessitated an evaluation of the liquid-penetrant inspection techniques already developed for the ceramic and cermet coatings when applied to the intermetallic coating.

\section{Experimental Work}

Three test specimens were prepared according to the design described in Fig. 2, p. 6. Specimens 22 and 23 had 0.5 -mm-thick ( 0.020 in.) plasma-sprayed CoCrAlY coatings on an alloy 800 substrate, and the specimen 24 had a 0.25 -mm-thick ( 0.010 in.) coating. The three specimens were cracked under tensile stress with cracks occurring at loads as follows: specimen 22 at $18 \mathrm{kn}(4000 \mathrm{lb})$, specimen 23 at $16 \mathrm{kn}$ (3550 1b), and specimen 24 at $17 \mathrm{kn}$ (3775 1b).

Radiographs showed that specimen 23 had one major crack (large enought to be seen without magnification) across the full width of the specimen throat (i.e., the point of minimum cross-sectional area) and several smaller cracks extending into the specimen from the edge of the throat. Specimens 22 and 24 each had one crack visible under microscopic examination. These cracks were narrower than the major crack in specimen 23. 

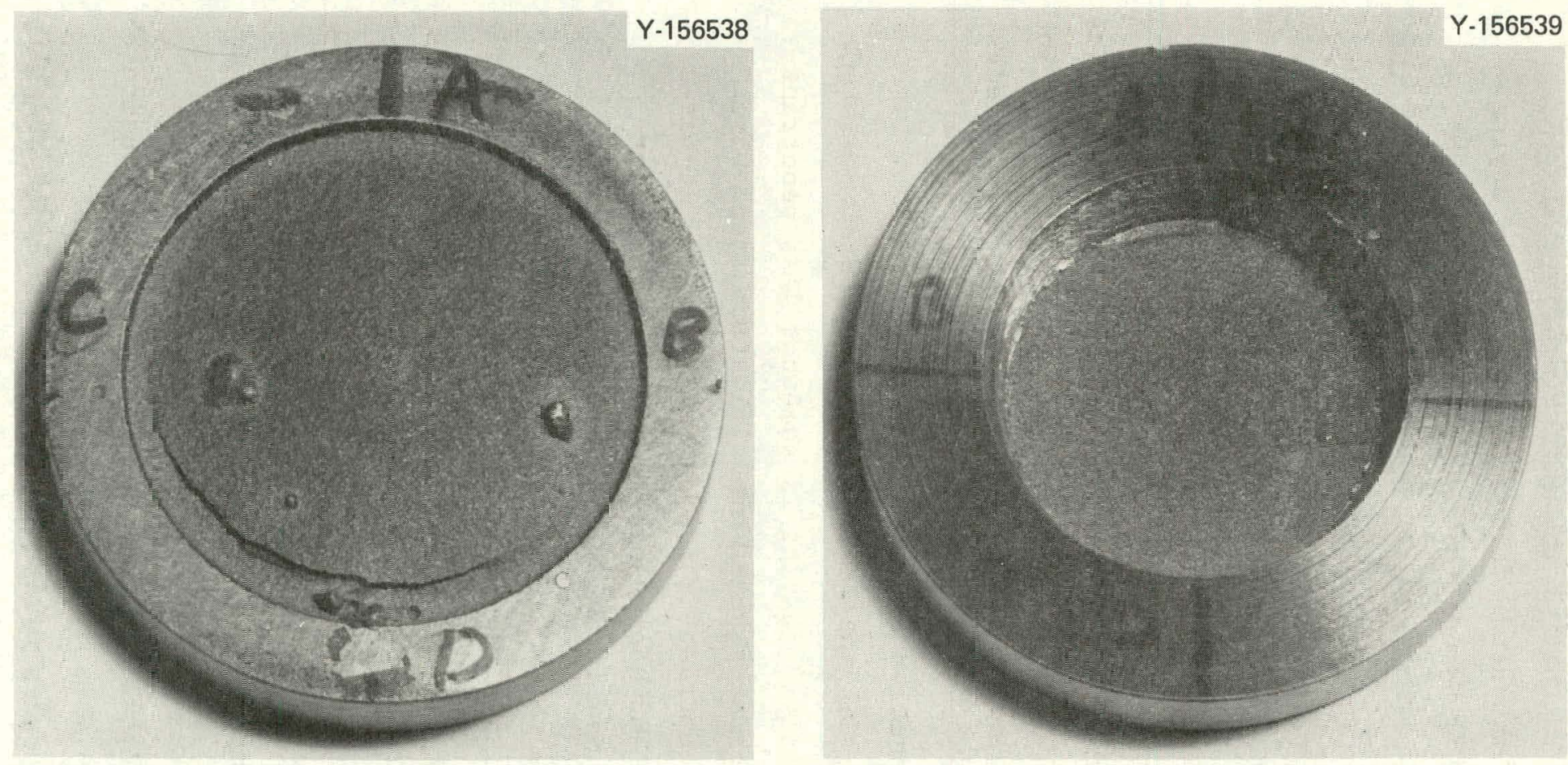
1
$2 \mathrm{~cm}$
(b)

Fig. 4. Free-Standing CoCrAlY Joating Layer, Disk Specimen 2. (a) Sprayed side. (b) Back, after backing metal was machined away. 
Specimen 23, having both wide and narrow cracks, was used for the tests with liquid penetrant. Since the cracking behavior of the intermetallic coating was similar to that of the cermet coating, ZL-22A liquid fluorescent penetrant was used, following the interim drying equilibrium augmentation (IDEA)-based procedure, 9 and cracks were

detected by the reversal process just as with the cermet coating. 8 The ZL-22A was brushed on the coating and, after a 20-min dwell was stripwashed for $2 \mathrm{~min}$ with a $26^{\circ} \mathrm{C} 0.2 \mathrm{MPa}$ ( $30 \mathrm{psi}$ ) water spray followed by forced air drying. Then the remaining penetrant was emulsified for 2 min, spray washed for 2 min, and dryed with forced air. Inspection under ultraviolet light immediately after the drying showed that sufficient penetrant was removed from the major and minor cracks to provide adequate contrast with the fluorescence from the penetrant remaining in the surrounding porous, uncracked coating for detection of these cracks.

\section{Discussion}

Apparently, the intermetallic coating is somewhat less penetrantretentive than the cermet because several emulsification steps were required to produce similar contrast in the cermet coating. It was shown for the cermet coating and appears to be true for the intermetallic that each emulsification step removes a "layer" of penetrant from the cracks in a larger amount than from the surrounding porous areas, making the process depend more on frequency (of emulsification) than on time. Thus, in practice the inspector would merely observe the surface after each emulsification; wash, and drying step. The number of emulsifications preceding crack appearances would provide a qualitative measure of crack sizes, since the wider cracks would appear after one or two emulsification steps and the narrower ones after several additional steps. This process also differs from many conventional methods by not using a developer. The work completed does not indicate that a developer is required or desirable. 
Conclusions

As was determined in the earlier work on ceramic and cermet coatings, 8 the porosity of plasma-sprayed coatings poses unique problems for surface inspection methods, especially those using liquids applied to the surface. These problems require significant alterations, such as IDEA, to traditional techniques, and, as in this case, modified methods of artifact detection and image interpretation. On the basis of the limited work done, liquid penetrant inspection of CoCrAlY coatings appears possible if modifications of traditional methods are used.

\section{RADIOGRAPHY}

G. W. Scott

Radiography might seem to be a poor substitution for simpler techniques that operate on or very near the coated workpiece surface. It is not generally accepted as a suitable method for crack detection, although it is acceptable for the detection of holes or other volumetric artifacts. Several factors favor its use for this application.

First, the as-sprayed metallic coatings are rough and porous. Surface inspection methods, such as liquid penetrant (liquid penetrant was the primary selection) are strongly affected by the porosity (see previous section, "Liquid Penetrant Testing"). Surface methods cannot detect cracks or voids inside the coating layer if they are not open to the surface.

Second, CoCrAlY coatings are moderately ferromagnetic (see "EddyCurrent Methods" later in this report). Eddy-current methods, the other backup: selection, require at least two discrete driving current frequencies to compensate for permeability and conductivity variation in the coating and substrate while measuring coating thickness. To detect defects, the effect of coating thickness would also have to be compensated for, and a third frequency would be required, making the design and use of the test somewhat complex. 
Third, radiography is independent of those material properties that interfere with the other two methods. It is unaffected by the electrical conductivities and magnetic permeabilities of the coating and the substrate. It is also less sensitive to gradual variations in the thickness of the coating, in the pore size, and in the volume fraction of porosity than to abrupt or step-type changes. Radiography would not be affected by any mechanical operations, such as peening, which might cover the opening of a defect to the surface, unless the shape or orientation of the defect were changed. Defects in a coating placed directly against an $x$-ray film acquire some contrast enhancement resulting from scatter (or buildup) in the surrounding coating and suffer minimal unsharpness because of their proximity to the film.

The primary objectives of this work were to: (1) evaluate the effectiveness of various radiographic techniques in detecting coating flaws, (2) determine the limits of sensitivity for radiography, (3) optimize the technique. The secondary objective was to identify any existing codes or standards, such as ASTM or ASME, that could be applied to radiographic inspection of coatings. Because of time and budgetary restrictions, not all these objectives were realized.

Theory

Coating inspection requires a technique optimlzed for detail sensitivity. (The other common type of technique is that optimized for thickness latitude.) Contrast and definition should be maximized. For experimental work, a method of determining sensitivity is also required. Current efforts have been directed toward techniques that place the coating film-side. If useful sensitivity can be demonstrated for these techniques, then techniques that place the coating source-side and possibly double-wall techniques should be investigated.

\section{Material Difference Between the Coating and Substrate}

Primary undisturbed radiation passing through a homogeneous medium 1s attentuated according to Lambert's law 10 


$$
I_{D}=T_{0} e^{-\mu x}
$$

where

$$
\begin{aligned}
& I_{0}=\text { the incident intensity, } \\
& \mu=\text { the linear attenuation coefficient, and } \\
& x=\text { the thickness of material. }
\end{aligned}
$$

Equation (1) always applies to narrow-beam geometry. Radiation falling on film in an $x$-ray setup also includes that portion scattered within the specimen and is expressed by the buildup factor $[B(\mu x)]$. The broadbeain intensity is

$$
I=I_{0} B(\mu x) e^{-\mu x},
$$

where

$$
\begin{aligned}
& I \quad=\text { the total transmitted radiation, and } \\
& B(\nu x)=\text { the buildup tactor. }
\end{aligned}
$$

The change in direct radiation caused by a flaw (as shown in Fig. 5) is obtained by differentiating Eq. (1):

$$
\Delta I_{D}=\cdots \Delta \Delta I_{0} c^{-\mu x}
$$

Radiographic contrast is the ratio of the change in direct radiation produced by a change in thickness to the total radiation,

$$
C= \pm \Delta I_{D} / I
$$

For the two-layered absorber shown in Fig. 5, the contrast is given by

$$
c-\frac{\mu_{2} \Delta x}{B_{1}\left(\mu_{1} x_{1}\right) B_{2}\left[\mu_{2}\left(x-x_{1}\right)\right]} .
$$

For a coating layer much thinner than its substrate, $x_{1} \approx x$ and buildup in the coating becomes negligible $\left(B_{2} \approx 1\right)$, so

$$
C=-\mu_{2} \Delta x / B_{1}\left(\mu_{1} x\right)
$$




\section{+ SOURCE}
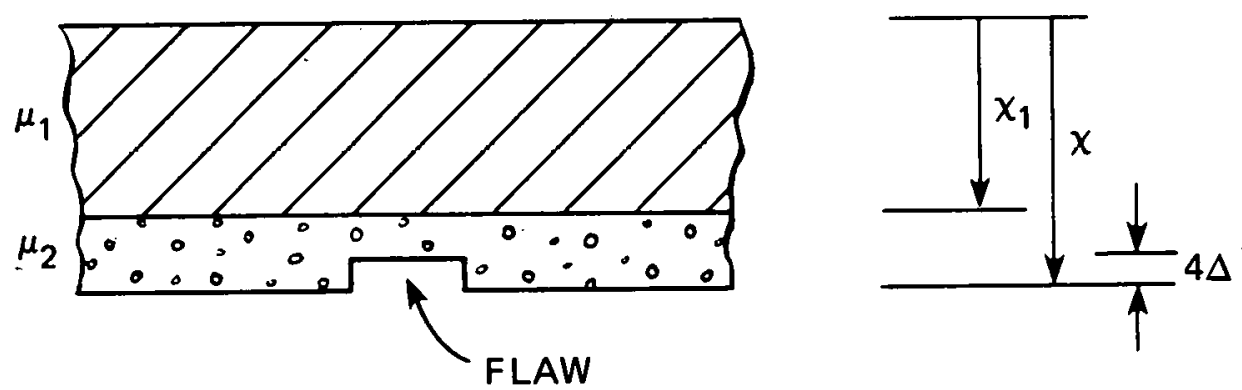

Fig. 5. Idealized Flaw Considered in X-Ray Attentuation Equations.

Thus contrast depends on buildup in the substrate and on attenuation and thickness change in the coating.

Porosity in the Coating Material

The mass attenuation coefficient $\left(\mu_{m}\right)$ for an alloy is given byll

$$
\mu_{m}=\frac{\mu}{\rho}=\sum_{i} \frac{\mu_{i}}{\rho_{i}} w_{i}
$$

where

$\rho_{i}=$ density of element $i$, and

$w_{i}=$ weight fraction of element $i$ in the mixture.

The property $\mu / \rho$ is independent of the density.

Plasma-sprayed coatings typically contain a significant void fraction. For them, $\mu / \rho$ remains constant and equal to $\mu_{0} / \rho_{0}$ (where the subscript zero refers to bulk, or fully dense, material) regardless of the coating density. The exponential factor, $\mu x$, can also be written as $(\mu / \rho)(\rho x)$, which equals $\left(\mu_{0} / \rho_{0}\right)(\rho x)$.

Therefore

$$
\mu x=\mu_{0} \alpha x,
$$


where

$$
\alpha=\rho / \rho_{0}
$$

Lambert's Law is then corrected to

$$
I=I_{0} \exp \left(\mu_{0} \alpha x\right)
$$

for the coating and the contrast [Eq. (6)] becomes

$$
C=-\mu_{20} \alpha x / B_{1}\left(\mu_{1} x\right),
$$

where

$\mu_{20}=$ the bulk linear attenuation for material 2.

The equivalent thickness of the coating relative to another material, such as the substrate, can be approximated by setting the exponential factors in Lambert's Law equal so that

$$
x_{2}=\left(\mu_{1} / \mu_{2}\right) x_{1}
$$

and for the case of variable density (porosity),

$$
x_{2}-\mu_{1} x_{1} / \alpha \mu_{20}
$$

This expression should be used only for approximating the effect of a thin layer, such as the coating, since it does not include buildup.

\section{Factors Affecting Definition}

Definition describes the ability of the viewer to discern the edges of an image area that concrasts with 1 Ls surruundings. Unsharpness and, to a lesser extent, film graininess, determine the definttion. of an image.

Film unsharpness, $U_{f}$, depends on film type, film processing, and the incident $x$-ray photon energy. For a high-sensitivity technique, one chooses a slow, fine grain film and low $x$-ray energy. Experimental measurements of $U_{f}$ are available in the literature. 12 
Geometric unsharpness is caused by the finite size of the radiation source (e.g., tube target, source pellet). The edge of any artifact creates a penumbral region where the film is exposed by radiation from only part of the source. In general, geometric unsharpness is given by 13

$$
U_{g}=S T / f
$$

where

$S=$ the source dimension in the plane of the beam, measured parallel to the plane of the film;

$T=$ the object-to-film distance, which may include the entire specimen thickness and does include specimen-to-film spacing;

$f=$ the source-to-film distance.

For coating radiography with the coating film-side, one may choose to ignore the unsharpness of images resulting from artifacts in the substrate. In this case, the specimen-to-film spacing becomes significant. Although the $U_{g}$ values for coating artifact images will be small, variations in coating-to-film spacing may increase them greatly.

Film and geometric unsharpness are not simply additive and many formulas have been developed for combining them. A commonly used empirical one is 14

$$
U_{T}=\left(U_{f}^{3}+U_{g}^{3}\right)^{1 / 3}
$$

$U_{T}$ is called the "total" unsharpness.

Filn graininess affects definition, but its interaction with unsharpness has not been exactly quantified. It remains constant when film type, density, and development are specified.

The Effect of Unsharpness on Contrast

Under certain conditions, the penumbral region of unsharpness in the projected image of an artifact can expand and cover the umbral 
region of the image. The resulting penumbral image has less contrast than the corresponding umbral image would have. A prenumbral image occurs when

$$
w<S x / f,
$$

where

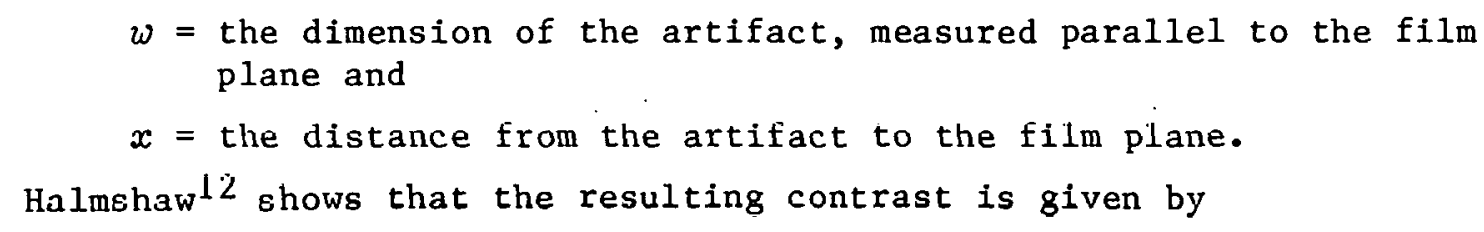
plane and

$x=$ the distance from the artifact to the film plane.

Halmshaw 12 shows that the resulting contrast is given by

$$
C^{-}=C w / U_{g}
$$

For fine cracks or small holes, $w$ will almost certainly be less than $S$, and $x$ is always less than $f$, so loss of contrast can be expected, even for those fortuitously oriented cracks or segments of cracks that are optimally imaged. The best one can do is keep $x$ as near $T$ as possible and adjust $f$ to reduce $U_{g}$ as far as other factors, such as exposure, allow.

\section{Experimental Work}

Initial experiments were directed toward determining the effects of buildup on contrast [as expressed in Eq. (14)]. We made test radiographs to determine the optimum exposure and development conditions for $3.2-, 6.4-$, and $9.5-\operatorname{mm}(0.12-, 0.25-$, and $0.38-i n$.$) thicknesses of alloy$ 800. The most common method of determining sensitivity or assuring its consistency uses an image-quality indicator, commonly called a penetrameter, so placed on the specimen that its image appears in the radiograph. American industry most often uses the so-called "plaque" penetrameter, which is a thin shim of radiographically similar material with right-cylindrical holes drilled through it. 
We qualified type 304 stainless steel for use as a penetrameter with alloy 800 in accordance with ASTM Standard E 142,15 although considerable radiographic experience shows alloy 800 more radiographically dense than type 304 stainless steel. Exposure at 130 and $140 \mathrm{kV}$ each yielded the required range of film densities and density differences (see Table 4).

Table 4. Penctrameter Test for Type 304 Stainless Steel and Alloy 800 at 6.35-mm (0.25-in.) Thickness

\begin{tabular}{|c|c|c|}
\hline \multirow{2}{*}{$\begin{array}{c}\text { X-Ray } \\
\text { Tube } \\
\text { Voltage } \\
(k V)\end{array}$} & \multicolumn{2}{|c|}{ Film Density } \\
\hline & $\begin{array}{c}\text { Type } 304 \\
\text { Stainless Steel }\end{array}$ & A1loy 800 \\
\hline 130 & 1.91 & 1.78 \\
\hline 140 & 2.33 & 2.17 \\
\hline
\end{tabular}

We evaluated these test radiographs to determine the thickness or contrast sensitivity attainable for relatively thin alloy 800 plates. All radiographs were made with a $300-\mathrm{kV}$ tungsten-target tube having a 5$\mathrm{mm}$ focal spot at a 1.37-m (54-in.) film focus distance. Kodak 5M10 lead-pack film was used. The film was processed in one of two ways: (1) by normal development, as recommended by the manufacturer, or (2) by the maximum overdevelopment allowable to increase contrast.

Image quality was controlled by a ser of experimental penetrameters, $160.075-, 0.10-$, and $0.13-\mathrm{mm}$-thick $(0.003-, 0.004-$, and 0.005-in.) type 304 stainless steel. Each of these penetrameters contains actual $1 T, 2 T$, and $4 T$ holes; for example, the $0.075-\mathrm{mm}$ penetrameter has hole diameters of $0.075,0.15$, and $0.30 \mathrm{~mm}$. Because these penetrameters are thinner than the minimum thickness of commonly available ASTM penetrameters, they are not certified, although they have been 
dimensionally inspected. The tube voltage and exposure (tube current $x$ time) were adjusted for optimum image quality.

Sensitivity was measured by observing penetrameter holes on each radiograph and converting to Equivalent Penetrameter Sensitivity by the ASTM-recommended formula: 17

$$
\alpha=\frac{100}{x} \sqrt{\frac{T h}{2}},
$$

where

$$
\begin{aligned}
& \alpha=\text { equivalent penetrameter sensitivity }(\%), \\
& \dddot{y}=\text { specimen th1ckness, } \\
& T=\text { penetrameter thickness, and } \\
& h=\text { penetrameter hole diameter. }
\end{aligned}
$$

\begin{tabular}{|c|c|c|c|c|c|c|}
\hline \multirow{2}{*}{$\begin{array}{c}x-\text { kay } \\
\text { Voltage } \\
(k V)\end{array}$} & \multirow{2}{*}{$\begin{array}{c}x-\text { Kay } \\
\text { Exposure } \\
(\mathrm{mA} / \mathrm{mIn})\end{array}$} & \multirow{2}{*}{ Development } & \multirow{2}{*}{$\begin{array}{l}\text { Film } \\
\text { Density }\end{array}$} & \multicolumn{2}{|c|}{ Penetrameter Visibility } & \multirow{2}{*}{$\begin{array}{c}\text { Equivalent } \\
\text { Penetrameter } \\
\text { Sensitivity } \\
(\%)\end{array}$} \\
\hline & & & & $\begin{array}{c}\text { Smallest } \\
\text { Hole }\end{array}$ & $\begin{array}{c}\text { Thickness } \\
(\mu \mathrm{m})\end{array}$ & \\
\hline \multirow{3}{*}{$\begin{array}{l}130 \\
140 \\
130\end{array}$} & \multicolumn{6}{|c|}{ 6.4-mm-thick (0.25-in.) Alloy 800 Plate } \\
\hline & $\begin{array}{l}35 \\
49 \\
75\end{array}$ & $\begin{array}{l}\text { Forced } \\
\text { Normal } \\
\text { Normal }\end{array}$ & $\begin{array}{l}3.59 \\
2.21 \\
2.30\end{array}$ & $\begin{array}{l}1 T \\
4 T \\
4 T\end{array}$ & $\begin{array}{l}10 \\
75 \\
75\end{array}$ & $\begin{array}{l}1.13 \\
1.4 \\
1.4\end{array}$ \\
\hline & \multicolumn{6}{|c|}{ 9.5-mm-th1ck (0.38-in.) A11oy 800 Plate } \\
\hline $\begin{array}{l}145 \\
130 \\
130\end{array}$ & $\begin{array}{l}180 \\
180 \\
180\end{array}$ & $\begin{array}{l}\text { Forced } \\
\text { Forced } \\
\text { Normal }\end{array}$ & $\begin{array}{l}3.90 \\
3.30 \\
2.22\end{array}$ & $\begin{array}{l}1 T \\
1 T \\
4 T\end{array}$ & $\begin{array}{l}10 \\
13 \\
10\end{array}$ & $\begin{array}{l}0.76 \\
1.07 \\
0.94\end{array}$ \\
\hline
\end{tabular}

The results are shown in Table 5 . A sensitivity of $1 \%$ may be a a practical lower 1imit; $2 \%$ sensitivity is a typical industrial standard.

Table 5. Equivalent Penetrameter Sensitivity for Alloy 800 Plates

We computed mass attenuation coefficients for nominal compositions of alloy 800 and CoCrAlY coating material to estimate relative thickness sensitivities. The data in Table 6 cover the photon energy range of most commercial x-ray sources likely to be used for radiography of sections between 6.4 and $25 \mathrm{~mm}$ ( 0.25 and $1 \mathrm{in.})$ thick. Since the mass 
attenuation coefficients differ by less than $10 \%$, the equivalent penetrameter sensitivites will differ by less than $10 \%$, so that the CoCrA1Y coating and alloy 800 substrate can be treated as equivalent for radiographic evaluation.

Table 6. Mass Attenuation Coefficients for Nominal Compositions of Alloy 800 and CoCrAlY Coatings

\begin{tabular}{ccc}
\hline \multirow{2}{*}{$\begin{array}{l}\text { Photon } \\
\text { Energy } \\
(\mathrm{keV})\end{array}$} & Mass & Attenuation Coefficient, $\mathrm{m}^{2} / \mathrm{kg}$ \\
\cline { 2 - 3 } & CoCrA1Y & Alloy 800 \\
\hline 80 & 0.0557 & 0.0616 \\
100 & 0.0352 & 0.0383 \\
150 & 0.0189 & 0.0200 \\
200 & 0.0142 & 0.0147 \\
300 & 0.0108 & 0.0111 \\
\hline
\end{tabular}

If the lower limit of thickness sensitivity is $1 \%$, then a defect such as a crack completely penetrating a $0.25-\mathrm{mm}\left(0.010-\mathrm{in}_{\text {. }}\right)$ coating could possibly be radiographically detected through a maximum substrate thickness of $25 \mathrm{~mm}$ ( 1 in.). Unfavorable orientation, crack width, and unsharpness, which must yet be investigated, will likely reduce that value significantly.

\section{Other Radingraphy}

To evaluate the tensile crack specimens (see Fig. 2, p. 6) used for liquid penetrant experiments, we routinely radiographed them with the film on the coating side. Figure 6 is an example. A few trials with film on the substrate side were made but yielded unsatisfactory results. No attempt was made to determine penetrameter sensitivity in these radiographs (in most cases no penetrameters were used), and development was nonstandard. A number of comparisons between radiographs and visual inspections were made, although no formal scheme was employed, and only descriptive records were kept. In most cases radiography showed more 
$\mathrm{Y}-165518$

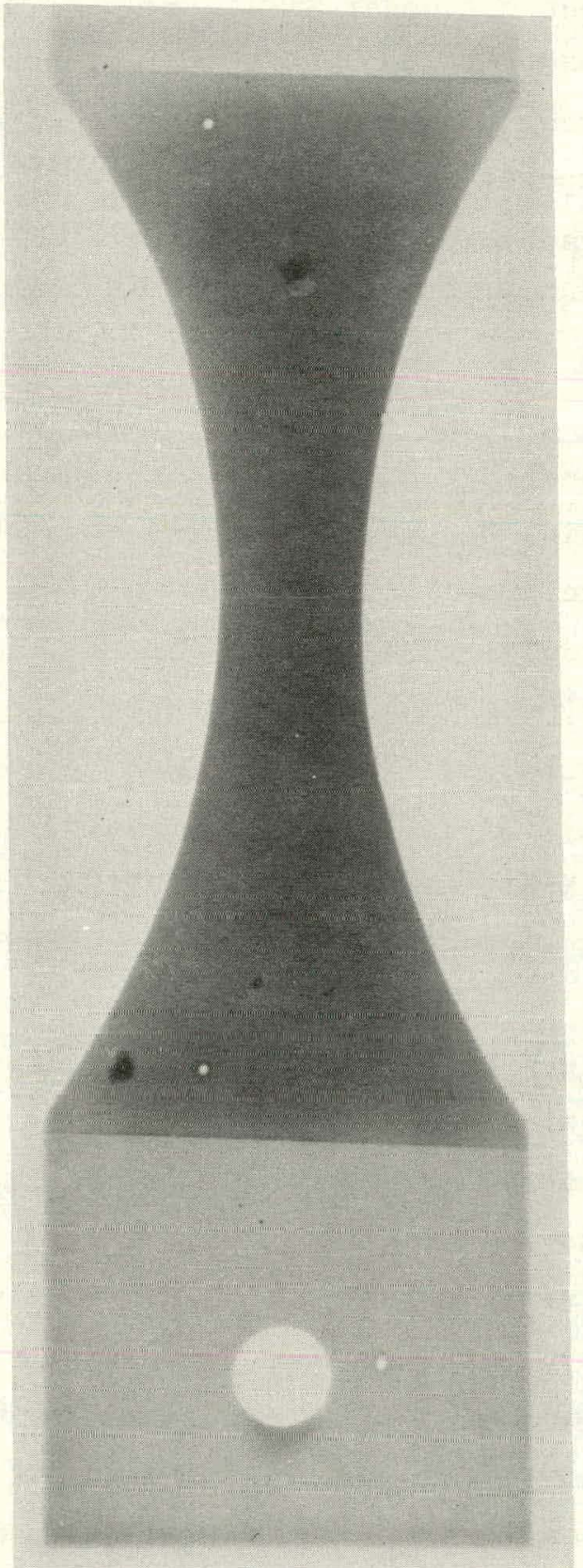

Fig. 6. Contact Print from Radiograph of Tensile Tested Specimen Showing Crack in CoCrAlY Coating. 
cracks than were visible to the eye, even when aided by magnifying optics and special illumination, such as side or polarized lighting. Some cracks that were apparently very tight showed under liquid penetrant inspection but not under visual inspection. Again, detailed comparisons were not made between the three methods, but it appears that radiography and penetrant showed similar degree of detail, and both were superior to visual inspection. Figure 6 is a contact print made from one of these crack radiographs.

\section{Conclusions}

The theoretical analysis indicates that with properly controlled exposure conditions, single-wall radiography with the coating film-side will successfully lmage small artifacts in thin coatings. The experimental data, though incomplete and not accurately documented for our "routine" applications, show that for relatively thin substrates cracks in the coatings can be imaged.

\section{X-RAY FLUORESCENCE TESTING}

G. W. Scott

$\mathrm{X}$-ray fluorescence (XRF) testing has been extensively applied as a substitute for wet chemical analysis of mixtures and, to a lesser degree, as a nondestructive technique for measuring the thickness of single-element coatings on substrates containing a single element or a large proportion of a single element. Measurement of the thickness of an alloy coating on an alloy substrate presents a combination of the mixture and layer-measurement problems.

Our investigation of this problem included a brief survey of available theoretical results, calibration work on our own new equipment, and some preliminary tests. 
Theory

\section{Fluorescence from Mixtures}

The intensity of a specific x-ray emission line for a specific element in a mixture depends upon: (1) the concentration of the element, (2) the availability of exciting radiation, (3) the fluorescence yield of the element, and (4) the ability of emitted radiation to leave the specimen and reach the detector. In compiling this listing, we assume a uniform specimen and uniform or correctable energy response by the detector.

Atoms receiving sufficient excitation, that is, equal to or greater than that of the $K$ absorption edge, preferentially emit $K$-series $x$-ray lines, with the highest yield for $K \alpha$ lines. For elements having atomic number, $Z$, equal to or less than about 50, higher order lines are difficult to measure, so the $K$ lines are exclusively used for XRF analyses. This $Z$ range includes all significant alloy constitutents of alloy 800 and CoCrA1Y coatings.

To illustrate the types of interactions that must be examined, we assume that a three-component mixture of elements $A, B$, and $C$, where $Z_{\mathrm{A}}>Z_{\mathrm{B}}>Z_{\mathrm{C}}$, is irradiated with incident photons of energy $E_{0}$, where $\bar{E}_{0}>K_{\text {edge, the }}^{\Lambda}$ absorpeion edge fur element $A_{i}$ (Wc know that $K_{\text {edge }}^{A}$ ) $K_{\text {edge }}^{3}>K_{\text {edge }}^{C}$ and that $K \alpha \alpha^{A}>K \alpha \alpha^{B}>K \alpha C$, where $K \alpha$ indicates the energy of a $K \alpha$ emission line. Spin-state differences, such as $K \alpha 1$ vs $K \alpha 2$, are 1gnored.)

At the specimen surface, all atomic excitations result from impinging photons $\left(E_{0}\right)$. Inside the material, other interactions are

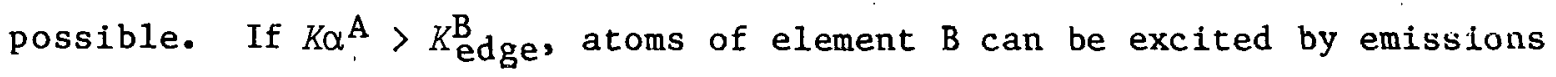
from element $A$ in addition to the $B$ atoms excited by source photons $\left(E_{0}\right)$, and the same is true for element $C$. Thus we have $A-B$ and $A-C$ interactions, called "mutual"18 or "interelement" 19 effects. Although the $K \alpha^{\mathrm{A}}$ photons are outnumbered by the $E_{0}$ photons, their effects may be comparable because the absorption cross-section, $\mu_{B}$, of element $\vec{B}$ may be much larger for photons of energy $K \alpha^{A}$ than for those of energy $E_{0}$. Sherman 18 has calculated these effects for three-component mixtures and verified the results by experiment. He distinguishes the interelement effects as follows: 
1. The $K \alpha^{\mathrm{A}}$ line has one component, resulting from the $E_{0}-\mathrm{A}$ interaction.

2. The $K \alpha^{B}$ line has one primary component, $E_{0^{-B}}$, and one mutual component, A-B (actually $E_{0}-\mathrm{A}-\mathrm{B}$ ).

3. The $K \alpha{ }^{C}$ line has the primary component, $E_{0}-\mathrm{C}$, two mutual components, $A-C$ and $B-C$ (Actually $E_{0}-A-C$ and $E_{0}-B-C$ ), and one "third-order" component, A-B-C (or $E_{0}-\mathrm{A}-\mathrm{B}-\mathrm{C}$ ).

An exception to this scheme, the absence of the $A-B$ component of $K \alpha^{\mathrm{B}}$, can occur if $K \alpha^{\mathrm{A}}<K_{\text {edge }}^{\mathrm{B}}$. Sherman's results form the basis of many computational schemes for extracting the composition of mixtures from $K \alpha$ Intensity data (see ref. 19).

\section{Fluorescence from Layers}

Birks 20 treats the problem of measuring a specific element in a mixture and specializes it to the case of thin layers. In this case, the measured $K \alpha$ intensity is proportional to the quantity of the element in mass per unit area.

Birks' Eqs. (5-1) to (5-5) can be combined to yield a singleelement result for a structure consisting of two mixed layers. The emergent intensity for element $i$ is given by

$$
I_{i}=Q_{i} I_{0 \lambda} \frac{\left[1-\exp \left(-\mu_{c}^{\prime \prime} \rho_{c} t\right)\right] \rho_{i c}}{\mu_{c}^{\prime \prime} \rho_{c}}+\frac{\rho_{i s} \exp \left[-\left(\mu_{c}^{\prime \prime} \rho_{c}+\mu_{s}^{\prime \prime} \rho_{c}\right) t\right]}{\|_{c}^{\prime \prime} \rho_{s}},
$$

where

$$
\begin{aligned}
& Q_{i \quad=} \begin{array}{l}
\text { excitation constant for } i \text { (equivalent to fluorescence } \\
\text { yield), }
\end{array} \\
& I_{0 \lambda} \quad=\text { the incident intensity at wavelength } \lambda \text {, } \\
& \prime_{c}^{\prime \prime} \text { and } \mu_{s}^{\prime \prime}=\text { absorption coefflclents for the coating and substrate, } \\
& \text { respectively, corrected for incoming and outgoing radi- } \\
& \text { ation energies and appropriate factors for broad or } \\
& \text { narrow beam geometry, } \\
& \rho_{c} \text { and } \rho_{i c}=\text { the densities of the coating and of element } i \text { in the } \\
& \text { coating, repectively, } \\
& \rho_{s} \text { and } \rho_{i s}=\text { corresponding values for the substrate, and. } \\
& t \quad \text { = the coating (outer) layer thickness. }
\end{aligned}
$$


If element $i$ is present only in the coating, then $\rho_{i s}=0$ and the second term drops out. A curve fitting this equation was obtained for measurements of $\mathrm{Zr} \mathrm{K \alpha}$ fluorescence from a $\mathrm{ZrO}_{2}$ coatingl of varying thickness $(t)$.

The response term $Q_{i} I_{0} \lambda$ could be determined experimentally from a specimen of pure element $i ; \mu_{c}^{\prime \prime}$ and $\mu_{c}^{\prime \prime}$ may be measurable by using a series of analyzed specimens. The various $\rho s$ can be determined from analysis; $\rho_{c}$ will require an estimate of coating porosity. Equation (1) would have to be incorporated into a complex scheme of equations involving all the constitutents and a simultaneous solution if discrimination against the effecls of composition and coating porosity var1ation is desired.

Energy and Emission Analysis of the CocralY Coat1ng Alloy 800 Substrate System

Resources did not permit the application of a complete analysis using the schemes previously discussed, $18-20$ so a qualitative energy method was substituted. Figure 7 shows the relations between the various $x$-ray energies involved. Table 7 summarizes the significant sources of the various line intensities.

'lhis analysis assumes: (1) that ail fluoresence yields for the various elements are approximately equal, with $K_{\beta}$ yields much less than $K \alpha$ yields, and (2) absorption (excitation) probability depends on relative element concentration, whether located in the coating or the substrate.

With these assumptions, the following estimates or predictions may be made.

1. Nickel and irnn line intensities decrease with increased coating thickness.

2. Cobalt intensity increases with coating thickness up to some limiting (i.e., effectively infinite) thickness.

3. Chromium line intensity either remains constant or decreases slowly with increased coating thickness. The ratios of other line intensities to that of chromium may provide improved thickness sensitivity. 
ORNL-DWG 79-18717

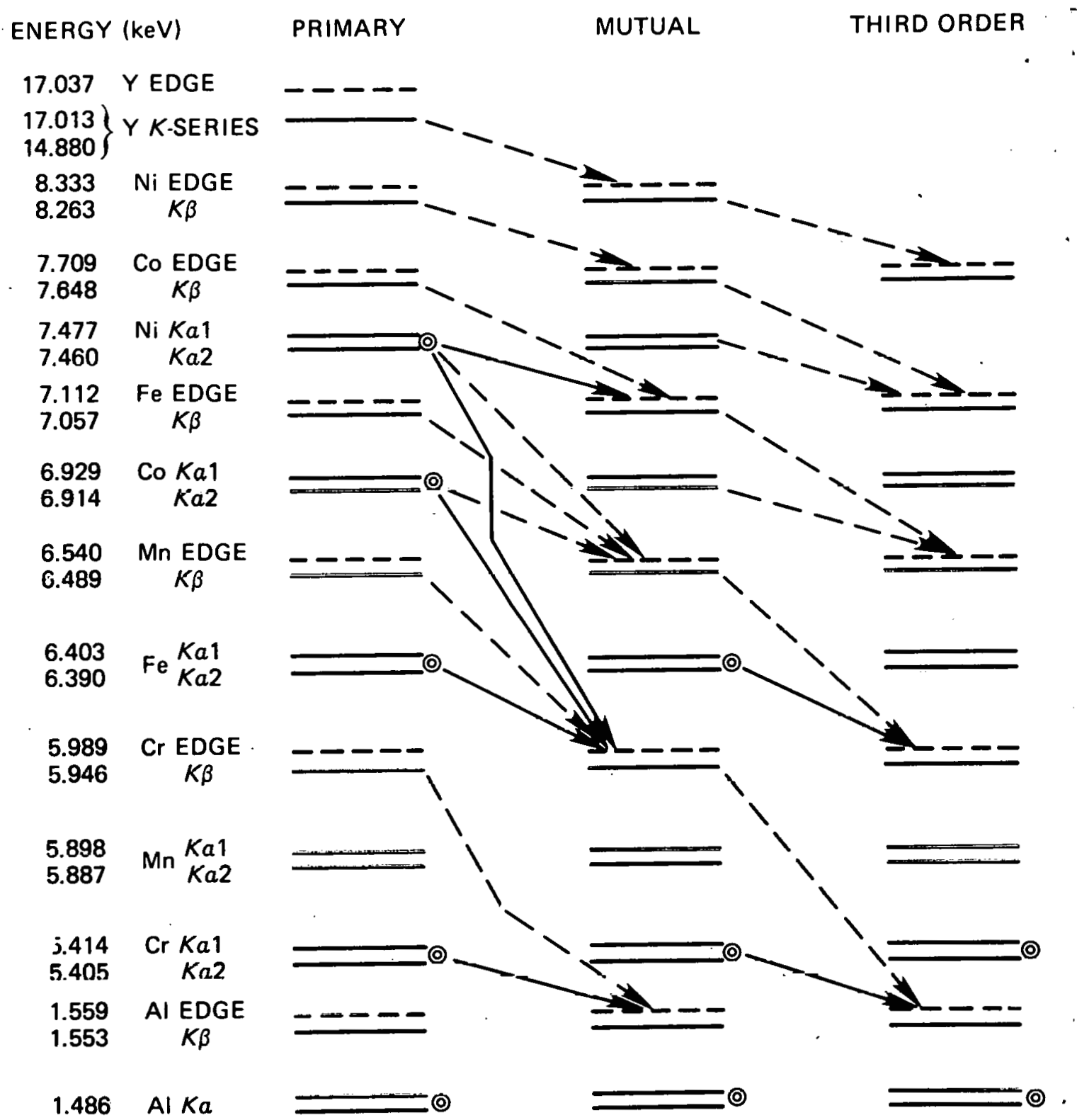

(๑) HIGHER INTENSITY LINES

- HIGHEST ENERGY INTERACTION POSSIBLE WITH SPECIFIC EMISSION ENERGY MOST LIKELY (HIGHEST INTENSITY) INTERACTIONS

Fig. 7. Energy Level Diagram Showing Possible Mutual and Thirdorder X-Ray Interaction in CoCrAlY Coatings on an Alloy 800 Substrate. 
Table 7. Mutual and Third-order Excitation

Sources for Significant Emission Lines

\begin{tabular}{lcc}
\hline Line & $\begin{array}{c}\text { Mutual } \\
\text { Excitation Sources }\end{array}$ & $\begin{array}{c}\text { Third-Order } \\
\text { Excitation Sources }\end{array}$ \\
\hline Ni $K \alpha$ & None & None $\cdot$ \\
Co $K \alpha$ & None & None \\
Fe $K \alpha$ & Ni $K \alpha$ & None \\
Cr $K \alpha$ & Ni $K \alpha$ & Fe $K \alpha$ \\
& Co $K \alpha$ & \\
Al $K \alpha$ & Fe $K \alpha$ & \\
& Ni $K \alpha$ & Fe $K \alpha$ \\
& Co $K \alpha$ & Cr $K \alpha$ \\
& Fe $K \alpha$ & \\
\hline
\end{tabular}

4. Aluminum line intensity increases with coating thickness, but its limiting thickness is likely to be very small because of its low. emission energy.

$$
\text { Experimental Work. }
$$

Two types of experiments were performed: those necessary to calibrate the system for the coating application and those to determine the sensitivity for this application.

\section{Calibration}

The source holder and detector shield for our syslemt uses a ringshaped source, $\dagger$ which produces a ring-shaped intensity distribution in Maine.

*Model NER-496, New Eligland Nuclear, Atomlight Place Billerica;

tIsotopes $109^{\mathrm{Cd}}$ or $153_{\mathrm{Gd}}$. 
planes near the source. For coating tests, it was necessary to locate a . plane over which the area seen by the $x$-ray detector received approximately uniform illumination.

First, the intensity distribution of the sources was determined by autoradiography. The sources were placed against a sheet of $x$-ray film. The developed images showed the relative intensity distribution for various locations around the source rings. Both sources were nonuniform, so they were marked to ensure that they were inserted in the same orientation each time.

The intensity distributions for potential sample locations were determined by placing. $x$-ray film in the sample plane and exposing. The developed images were measured along various scan directions with a densitometer to determine the intensity variation across areas seen by the detector. Satisfactory specimen locations were determined.

\section{Sensitivity Tests}

We ran sensitivity tests using known thicknesses of tool steel ( $>70 \% \mathrm{Fe}$ ) shim material. The results are shown in Table 8 .

Table 8. Fluorescence Response of Tool Steel Shims to ${ }^{153} \mathrm{Gd}$

Excitation

\begin{tabular}{|c|c|c|c|}
\hline \multicolumn{2}{|c|}{ Shim Thickness } & \multicolumn{2}{|c|}{ Counts in Each Peak } \\
\hline$(\mathrm{mm})$ & (in.) & Fe $K \alpha$ & Fe $K \beta$ \\
\hline 0.20 & 0.008 & $\begin{array}{l}38914 \\
38956 \\
38724\end{array}$ & $\begin{array}{l}6664 \\
6700 \\
6604\end{array}$ \\
\hline 0.28 & $0.011^{b}$ & $\begin{array}{l}40142 \\
40341 \\
40221\end{array}$ & $\begin{array}{l}6883 \\
6929 \\
6969\end{array}$ \\
\hline
\end{tabular}

$a_{\text {Concurrent } 100-s \cdot \text { counts, cor- }}$ rected for background.

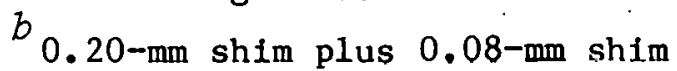
behind; front shim at same distance as before. 
Discussion

The sensitivity test results are likely somewhat optimistic, since the tool steel contains a higher percentage of iron than either the coating or substrate materials under consideration. Some tool steels contain significant percentages of other elements, such as cobalt, vanadium, and tungsten, so some interelement effects may be present. There are no effects of step changes in element concentrations, as would be present in coated specimens.

The data Indicate that \& $257 \mathrm{~m}$ (0.001-in.) shange in shim thickness would produce approximately $1 \%$ change in total counts for the $\mathrm{Fe}$ line. Detection of thickness changes would thus require detections of small changes in large numbers. If $n$ is the total number of counts, statistical counting errors are proportional to $\sqrt{n}$. To reduce statistical errors to $10 \%$ of the count change per $25 \mu \mathrm{m}$ ( 1 mil) would require $n \approx 10^{6}$ counts, which at the count-rates obcalned would takc $2.5 \times 10^{3} \mathrm{~s}$ to accumulate.

\section{Connr.lusions}

The sensitivity obtained with a single-element line count indicates chat a $0.25 \mathrm{~mm}(0.010-i n$.$) snating of elements with atomic number$ $Z$ near that of iron on a substrate of similar compostion would be near the useful limits of the XRF method. The testing of actual coated specimens would be useful. The investigation of more sophisticated analytical schemes for XRF measurement of coating thickness would be highly desirable.

EDDY-CURRENT ME'THODS

$$
\text { G. W. Scott }
$$

A11 eddy-current methods are based on the response of workpiece materials to electromagnetically induced electric currents. Ihe generation of those currents in a workpiece depends on several factors: 
(1) the strength, frequency, and geometry of the inducing field; (2) electrical resistivity and magnetic permeability of the workpiece material; and ( 3 ) any gaps, flaws, layers, or other artifacts producing rapid changes in electrical properties within a small volume of the material. The response of the workpiece is measured either as an impedance change in the inducing (driver) coil or as currents induced from the material into a second (pickup) coil.

Eddy currents were first used nearly 100 years ago for sorting metals. Since then, they have been used to measure electrical properties, to measure thicknesses of single and multiple layers of conductors, and to detect defects. Eddy-current measurements can indicate other conditions that correlate well with electrical properties, such as heat treatment in steels. The eddy-current method was selected as the primary one for coating thickness measurement and as a backup for crack and hole detection.

Early eddy-current inspection procedures were developed by trial and error and other empirical methods; many are still developed this way. Modern methods of inspection development and equipment design use solutions to the electromagnetic field equations generated by digital computers from analytical approximations. These methods apply to new instrument designs and can also be used to optimize the application of existing commercial instruments. The inspection problem can be optimized by designing special equipment, such as coils, or by selecting the best operating conditions for existing instruments.

The phase-eenoing unbalanced bridge Instrumencs 21,22 and inductively coupled reflection-type probe coil (Fig. 8) developed at ORNL have repeatedly demonstrated the ability to measure the thicknesses of single conductors and metallic coatings or claddings on metal substrates with high accuracy. 23,24 Defect detection in multiconductor systems has also been accomplished. A well-established methodology exists for the design of probe coils, instruments, and testing schemes. 25 However, the design of a test to measure the thickness of CoCrAlY coatings does present some challenging problems.

First, modern computer-aided design optimization requires at least base line estimates of electrical resistivity and magnetic permeability 


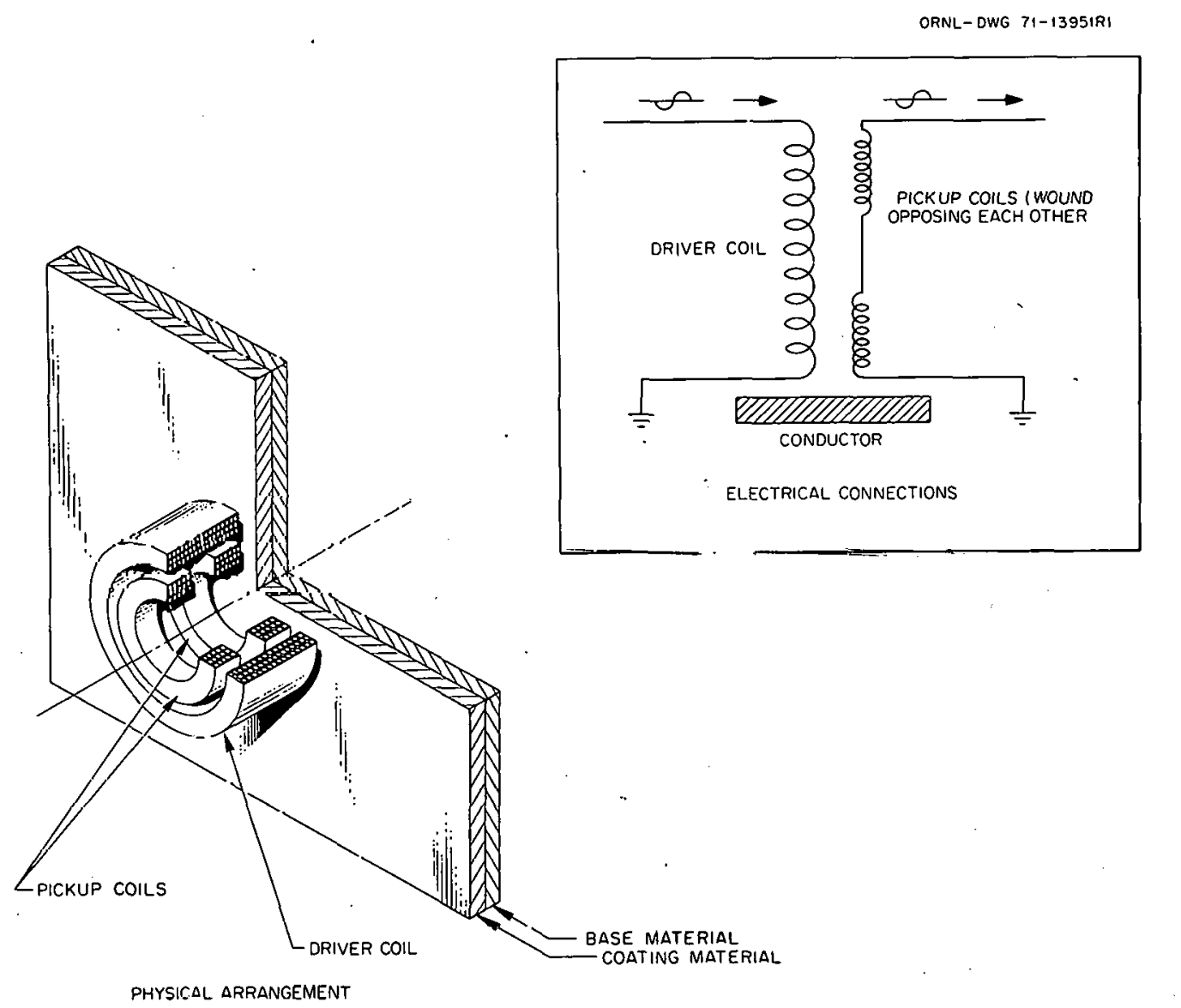

F1g. 8. Physical Arrangement and filectrical Schematic of a Reflection-Type Eddy-Current Coil System.

of the coating material. Few measurements have been made and reported on plasma-sparayed materials, and none for CoCrAlY were located by our 1iterature search.

Second, simple magnetic attraction tests shuwed that the placmasprayed CoCrAlY is ferromagnetic. Pure cobalt has a relative permeability, $26 \mu_{r}$, of $6 U$; it is the unly feirumagnctio sonstituent alement of the spray powder. Since the powder contains about $63 \%$ Co we antlicipated that the cuating ahnuld have a permeahility between 1 and 60. The occurrence of ferromagnetism in the coating material created two uncertainties: (1) the choice of a value of $\mu_{r}$ that would be effective for the eddy-current situation and (2) the effect of permeability on our progammed equations, which heretofore had been used only on paramagnetic or diamagnetic materials, always assuming $\mu_{r}=1$. Although a number of inspection problems-on-ferromagnetic materials have been solved, 27-29 computer-aided design and instrument simulations were not directly applied. 
Multiparameter Tests

The impact of added conductor layers and defect occurrence on the complexity of eddy-current tests is best understood in terms of multiparameter test theory. Each conductor is defined to have three properties: electrical resistivity $(\rho)$, magnetic permeability $(\mu)$, and thickness. If defects are introduced into a stack of conductors having parallel planar boundaries, each defect can be characterized by its radial location relative to the probe coil axis, its vertical location relative to the boundary planes, and its volume. (Volume is reduced to the radius of a sphere having equal volume.) Thus, defects also have three properties. For cylindrical reflection coils and coaxial transmission coils with axes normal to the conductor planes lift-off (spacing between the coil and the conductor) must also be considered; it is treated as an additional single property.

Thus, a system of $n$ conductors has $3 n$ conductor properties, $3 n$ defect properties (assuming one defect per conductor), and the lift-off for a total of $6 n+1$ properties. A coated metal system, including 'two conductors, has 13 possible properties. Each property requires one independent measurement for its determination or to discriminate against its effects, and each discrete test frequency yields two independent measurements (a magnitude and phase of plckup coll output voltage). Therefore, a system of $n$ conductors required $3 n+1$ test frequencies (leaving one measurement unused). A two-conductor system would require 7 discrete measurement frequencies.

Clearly, some degree of simplification is necessary to make even simple systems manageable with existing equipment. There are two alternatives: (1) controlling specific properties so that either no variation occurs or the exact value is always known or (2) ignoring the possible variation in certain properties. Alternative (2) is not equivalent to omitting a property measurement from a test; in a valid test design, all variable properties must be included, even if they are not to be measured, so that adequate discrimination can be achieved. When the possible variation in a property is ignored, the designer gambles that it will not occur and accepts the risk that its occurrence can interfere with measurement of or discrimination against other property variations. 
In many cases, material characteristics assist the designer. Nonmagnetic materials have permeabilities sufficiently close to unity that variations can be safely ignored. Very thick substrates (lowermost conductors) can be treated as infinitely thick and therefore constant in thickness.

When defects are confined to a single layer (ignoring those in other layers), their radial location relative to the coil axis can be set constant. 30 Experience shows that for defects small relative to coil dimensions defect response is typically a linear function of volume, 30 so only a single value of defect size may be needed. Some property-control methods are available. Saturating devices built into the probes can hold permeability constant and sometimes reduce it to unity in thin-wall tubes and thin coatings. 31

The combination of several assumptions and control methods can drastically reduce the complexity of a rest, as shown in Table 9.

Table 9. Property Variation with Successive Simplifying Assumptions in a Two-Conductor (Coating-Substrate) System

\begin{tabular}{|c|c|c|c|}
\hline Case $e^{\alpha}$ & As sumptions & $\begin{array}{l}\text { Remaining } \\
\text { Variable } \\
\text { Prupeities }\end{array}$ & $\begin{array}{c}\text { Test } \\
\text { Frequencies } \\
\text { Required }\end{array}$ \\
\hline 1 & None & 13 & 7 \\
\hline 2 & $\begin{array}{l}\text { Constant substrate } \\
\text { permeability }\left(\mu_{1}=1\right)\end{array}$ & 12 & 6 \\
\hline 3 & No defects in the substrate & 9 & 5 \\
\hline 4 & $\begin{array}{l}\text { Constant radial location for } \\
\text { coating defects }\end{array}$ & 8 & 4 \\
\hline 5 & Infinitely thick substrate & 7 & 4 \\
\hline 6 & $\begin{array}{l}\text { Ma gnetical1y saturated } \\
\text { coating }\left(\mu_{2}=\text { constant }\right)\end{array}$ & 6 & 3 \\
\hline 7 & $\begin{array}{l}\text { Constant substrate } \\
\quad \text { resistivity }\left(\rho_{1}=\text { constant }\right)\end{array}$ & 5 & 3 \\
\hline 8 & No defects in the coating & 3 & 2 \\
\hline 9 & $\begin{array}{l}\text { Constant coating } \\
\text { resistivity }\left(\rho_{2}=\text { constant }\right)\end{array}$ & 2 & 1 \\
\hline
\end{tabular}

$a_{\text {Each }}$ successive case incudes all the assumptions listed down to that point. 


\section{Single-Frequency Test Design}

Before any coating materials or specimens were available, we elected to investigate the response of a thin coating to a singlefrequency test, and so considered several examples of Case 9. The design was to be governed by the following constraints:

1. The coating thickness range was 0.13 to $0.51 \mathrm{~mm}(0.005-$ 0.020 in.); we solved the desin problem for thicknesses of $0.13,0.25$, and $0.51 \mathrm{~mm}$.

2. The inspection would use an ORNL reflection coil design, shown schematically in Fig. 9.

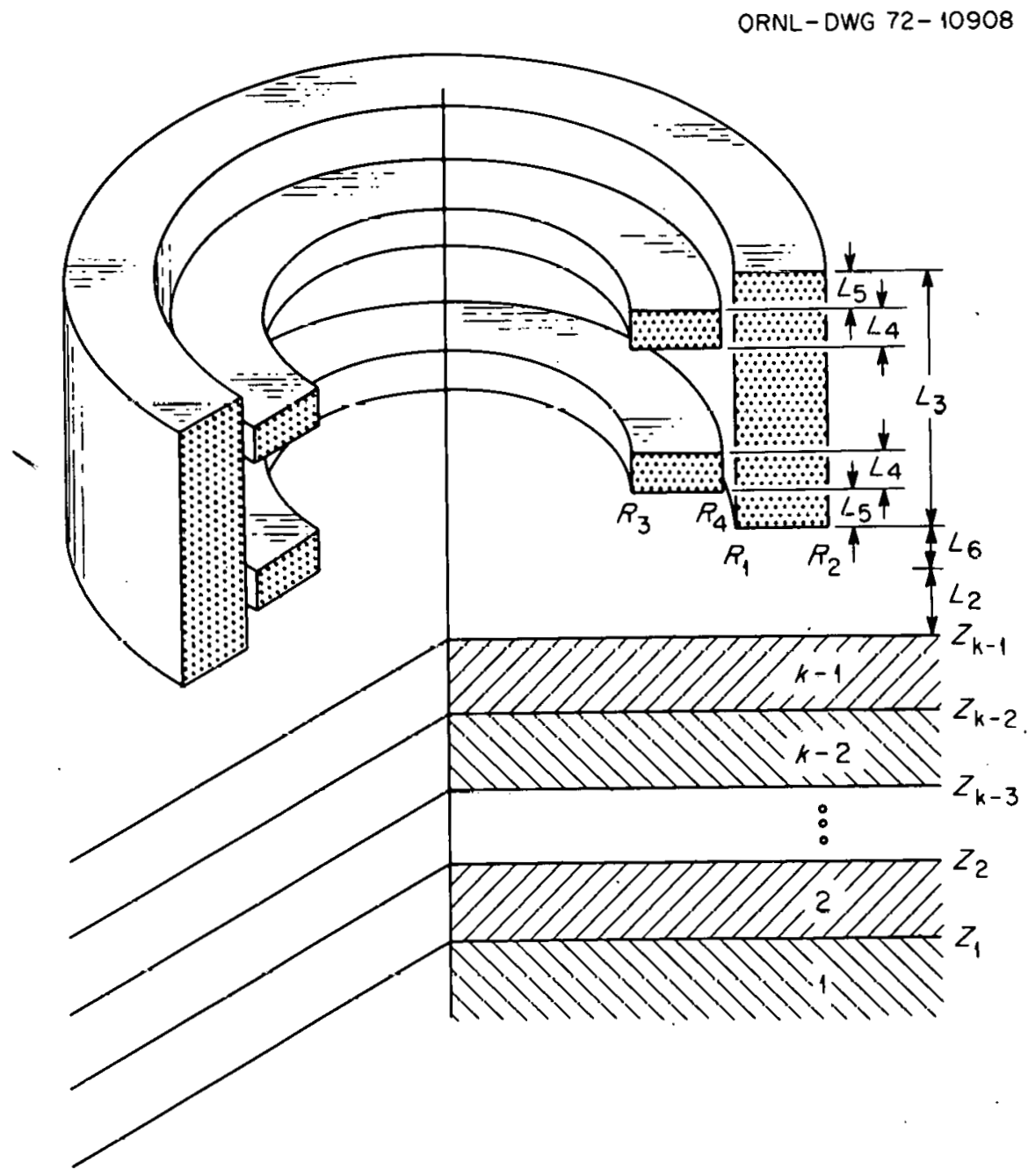

Fig. 9. ORNL Reflection Coil Design and Geometrical Parameters Used for Calculations. 
3. Existing coils are available in discrete sizes; the smallest coil has a mean driver coil radius, $\bar{r}$, of $0.51 \mathrm{~mm}(0.020 \mathrm{in.})$.

4. The maximum frequncy at which a reflection coil has been successfully operated is $20 \mathrm{MHz}$; oscillators in existing equipment are scaled in $1,2,5$ sequence (e.g., 100, 200, $500 \mathrm{kHz}$ ).

The resistivity of the alloy 800 substrate, $\rho_{1}$, was approximated as $1 \mu \Omega \mathrm{m}(100 \mu \Omega \mathrm{cm})$ (reported measurements are $0.98-0.99 \mu \Omega \mathrm{m}$ ). The resistivity of the coating, $\rho_{2}$, was estimated as $10 \mu \Omega \mathrm{m}(1000 \mu \Omega \mathrm{cm})$; values of 5 and $40 \mu \Omega \mathrm{m}$ were included. We assumed that $\rho_{1}$ and $\rho_{2}$ vary less than 1\%. Coating and substrate permeability variation was 1gnored; we inttially assumed $\mu_{1}=1_{2}=1$.

Figure 9 describes, in addition to the probe coil, the two-layer conductor problem that must be solved. For computation, all actual dimensions are normalized in terms of the mean radius of the driver (outside) coil, which is given by

$$
\bar{r}=\left(\mathrm{r}_{1}+r_{2}\right) / 2 \text {. }
$$

Capital letters indicate normalized dimensions $\left(R_{1}=r_{1} / \bar{r}, L_{1}=\eta_{1} / \bar{r}\right.$, etc). A significant parameter recurring in the calculations is $\omega \mu \sigma \bar{r}^{2}$, where $\omega=$ angular frequency $(\omega=2 \pi f$, with $f$ in $\mathrm{Hz})$. Another parameter is $C$, the normalized coating thickness (thickness $/ \bar{r}$ ).

We have a large backlog of data accumulated from computer-aided exact solutions to the eddy-current field equation. Most of these solurions have been verified by experiment, so the computer data form a usetul basts for the optimized design of new test systems.

For single- and multiple-layer measuring applications, phasesensing methods are superior to amplitude-sensing ones, because they can discriminate against errors caused by variations in lift-off. A twolayer system has an optimum value of $C$ for each value of the conductivity ratio, $\sigma_{1} / \sigma_{2}$. Figure 10 shows the phase shift (instrument response) for a $10 \%$ change in coating thickness vs $C$ when $\sigma_{1}=0.1$ (e.g., $1 / \sigma_{1}=10 \mu \Omega \mathrm{m}$ and $1 / \sigma_{2}=1.0 \mu \Omega \mathrm{m}$ ). This figure also shows the values of $\omega \mu_{1} \sigma_{1} \bar{x}^{2}$ for maximum sensitivity to coating thickness variation as a function of $C$. We have similar graphs for $\sigma_{1} / \sigma_{2}=0.025\left(1 / \sigma_{1}=\right.$ $40 \mu \Omega \mathrm{m})$. 


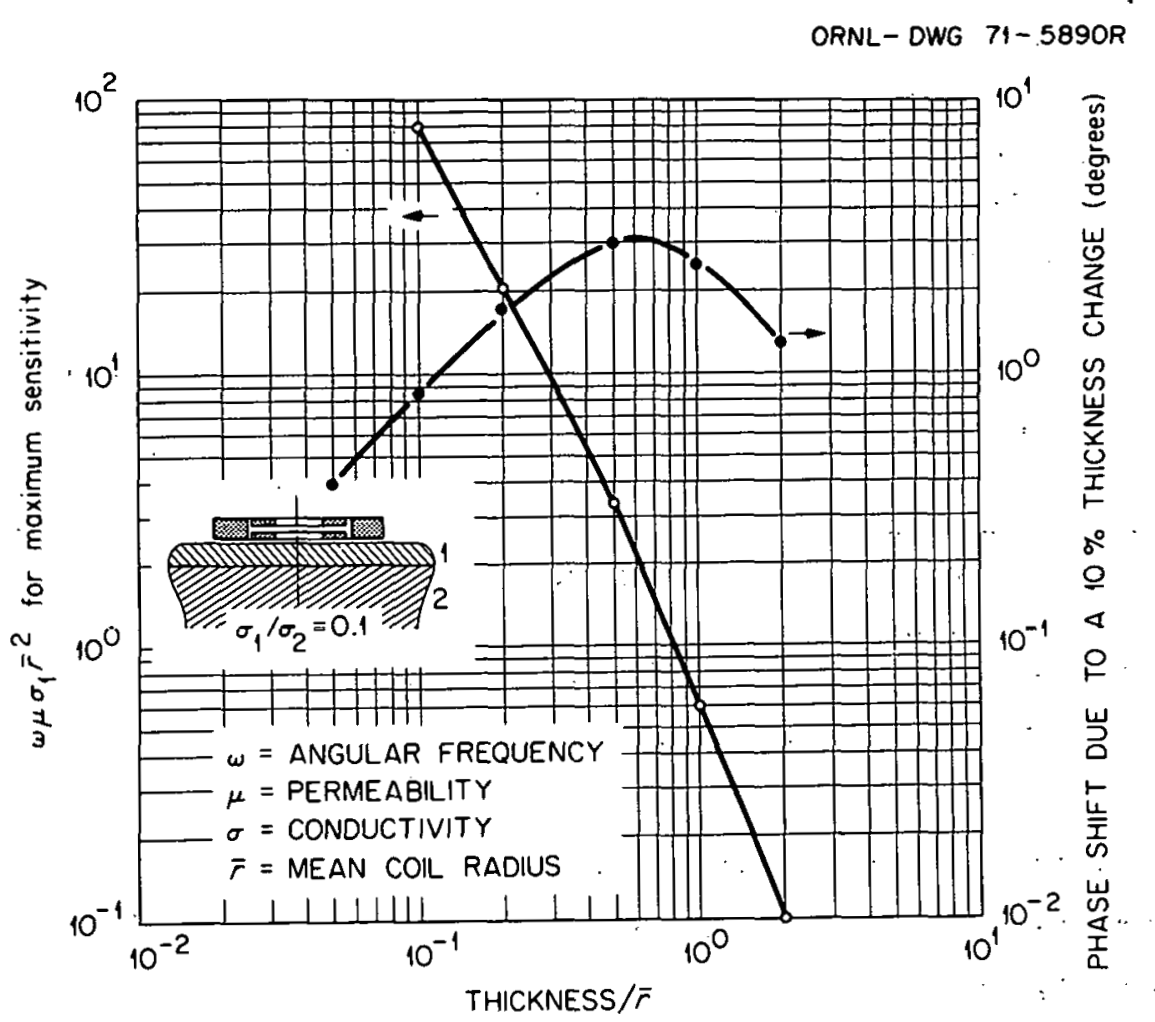

Fig. 10. Instrument Response (Phase Shift) and Optimum Values of $\omega \mu_{1} \sigma_{1} \bar{r}^{2}$ vs Normalized Coating Thickness for $\sigma_{1} / \sigma_{2}=0.1 .$.

The optimum value of $C$ in Fig. 10 is about 0.6 . For an actual coating thickness of $0.25 \mathrm{~mm}(0.010 \mathrm{in}$ ), the optimum coil size would be $\bar{r}=0.25 / 0.6=0.42 \mathrm{~mm}(0.017 \mathrm{in.})$. The smallest coil we have has $\bar{r}=$ $0.51 \mathrm{~mm}(0.020 \mathrm{in}$.), for which $C=0.5$. The phase shift maximum is broad, so performance would be acceptable for $C=0.5$.

The optimum value of $\omega \mu_{1} \sigma_{1} \bar{r}^{2}$ can be determined from Fig. 10. (or similar graphs) when $C$ is known. Since all the factors except $\omega$ are known, the operating frequency can be calculated. We looked up the $\omega \mu_{1} \sigma_{1} \bar{r}^{2}$ values. from appropriate graphs and computed the resulting frequencies; the usable frequencies are listed in Table. 10. ...

Several conclusions could be drawn from Table 10. First, tests for coatings significantly less than $0.25 \mathrm{~mm}$ ( $0.10 \mathrm{in}$ ) thick may be impossible to optimize. Second, tests for thinner coatings with resistivities greater than $10 \mu \Omega \mathrm{m}$ would be difficult to optimize. If 
Table 10. Optimum Eddy-Current Frequencies for Coating Thickness Measurement

\begin{tabular}{|c|c|c|c|c|}
\hline \multirow{2}{*}{$\begin{array}{l}\text { 1, Coating } \\
\text { Resistivity } \\
(\mu \Omega \mathrm{m})\end{array}$} & \multirow[t]{2}{*}{$\sigma_{1} / \sigma_{2}{ }^{a}$} & \multicolumn{3}{|c|}{$\begin{array}{c}\text { Frequency, MHz, for Each Normalized } \\
\text { Coating Thickness, } c^{b}\end{array}$} \\
\hline & & 0.25 & 0.50 & 1.00 \\
\hline 40 & 0.025 & $>20^{c}$ & $>20^{\circ}$ & 9.8 \\
\hline 10 & 0.1 & $>20^{c}$ & 16 & 2.9 \\
\hline 5 & 0.2 & $>20^{c}$ & 8.6 & 1.8 \\
\hline \multicolumn{5}{|c|}{ 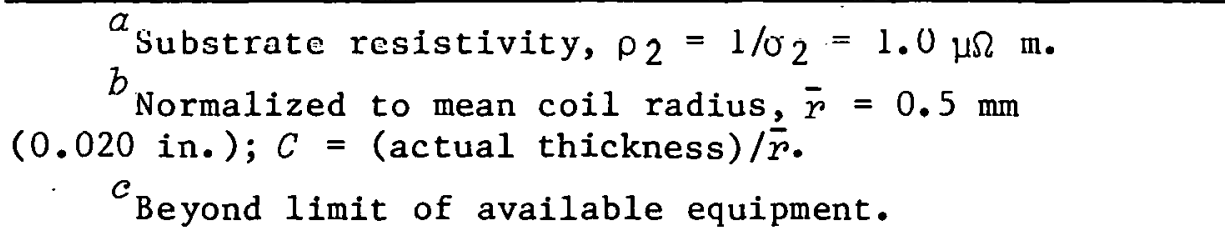 } \\
\hline
\end{tabular}

postspraying densification (e.g., by peening) decreases resistivity by a greater fraction than it decreases thickness, some improvement in inspectability may occur.

The next step would have been to compute errors caused by conductivity and lift-off variations. We deferred this step until the conductivity and permeability of the coating were estimated.

\section{Électrical and Magnetic Property Measurements}

The first available free-standing CoCrAlY coating-layer specimen (No. 2) when tested for magnetic attraction displayed ferromagnetic behavior. The single ferromagnetic constitutent, cobalt, has a handbook value of 60 for relative permeability, $\mu_{r}$, so 60 was used as the upper limit for calculations.

A review of etandard methode 32 for mcasuring permeahility produced 19 different definitions of effective permeabilities that can be measured in materials under various testing conditions. This variety 
results because magnetization is not a linear function of magnetizing force in ferromagnetic materials, and the relationship differs between different types of ferromagnetic materials. (Effective permeability is the instantaneous rate of change of magnetization with magnetizing force.) The various standard methods were all eliminated from consideration because of specimen requirements, magnetization conditions, or insufficient ranges of test frequencies.

During some radiographlc testing of alloy 800 , we noted a motting of the metal's image on the film. We located other specimens of alloy 800 for comparison and found that their radiographs did not show mottling. We compared the two groups of specimens with an approximate eddy-current conductivity measurement using interpolation of the response between values obtained from known standard materials. Specimens with clear radiographs had resistivities of around $1.06 \mu \Omega \mathrm{m}$, while the resistivities of those with mottled radiographs were around $1.02 \mu \Omega \mathrm{m}$. Both values are greater than those published in the technical literature, 0.98 to $0.99 \mu \Omega \mathrm{m}(98$ to $99 \mu \Omega \mathrm{cm})$. We have no data to show whether or not the observed variation is typical of alloy 800 . Therefore, the conservative approach to eddy-current design must allow for variation in the substrate (alloy 800 ) conductivity. Two frequencies will be required either to measure coating thickness or to detect defects in the coating, because the substrate conductivity varies. If permeability variations appear, a third frequency may be required.

Conductivity can be measured with a single-frequency eddy-current instrument when specimen thickness is known and the material is nonmagnetic. When the material is ferromagnetic, the theoretical problem requires two frequencies for solution unless both specimen thickness and probe lift-off can be rigidly controlled. In practice, some effort toward thickness and lift-off control combined with a two-frequency measurement can significantly improve confidence in the results. Resistivity and permeability can, in theory, be measured indirectly and simultaneously by an instrument having wel1-characterized geometric and circuit parameters. Because resistivity and permeability changes affect eddy-current response much less than changes in lift-off, the 
elimination or control' of lift-off effects is highly desirable in electrical property measurement. The fixed coil spacing in the throughtransmission configuration (Fig. 11) assures that the sum of lift-off and specimen thickness remains constant; accurate measurement of the specimen thickness yields comparable accuracy in the value of lift-off. The axial position of the specimen between the coils does not affect the response, and the remaining parameters of the instrumentation can be measured with sufficient accuracy that the error contributions can be i gnnred.

The measurement of amplitudes and phase of the voltage across the receiving (pickup) coil providec two numbers and allnws lle calculation of the unknown material properties. Corroborative data can be obtained by repeating the measurement at various frequencies. We elected to attempt development of a technique to use measurements taken at two frequencies to compute permeability and resistivity; this method would not require measurements, of either the coil spacing or the specimen thickness.

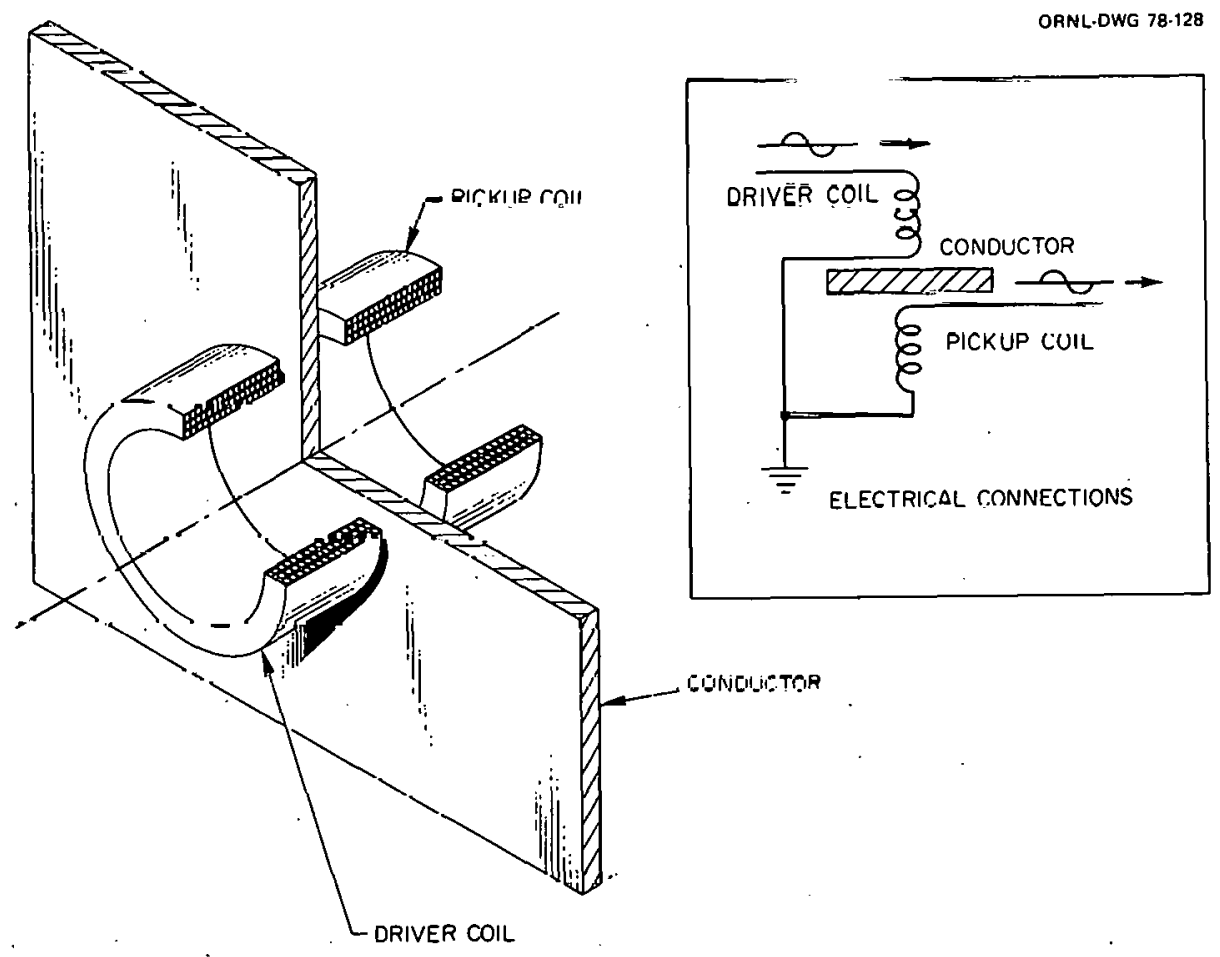

PHYSICAL ARRANGEMENT

Fig. 11. Physical Arrangement and Electrical Schematic of a Through-Transmission Eddy-Current Coil System. 
The design and application of an eddy-current method to simultaneously measure electrical resistivity and magnetic permeability offered the prospect of getting the property data required for a reflection-coil thickness test design and the opportunity to test parts of our reflection-coil simulation programs for $\mu_{r}>1$. The design and simulation computations for a through-transmission system use the same basic field equations as the reflection-coil computations, but combine intermediate results differently. The through-transmission program, MULTRU, was developed as part of a family of programs for solving induction problems involving cylindrical coils parallel to structures of planar conducting layers; details of its structures and use are documented elsewhere. 30 The through-transmission coil arrangement (Fig. 11) offers control over lift-off, sensitivity to material properties, and noise immunity superior to that of the reflection coil, but the systems use identical modular electronic components, so no special modifications were required.

Measurement of unknown material properties forced a change in the strategy of program use. In most design problems, the properties are known, so nominal values and small ranges of expected variation are inserted into the programs. The calculations are then repeated with various coil designs, circuit parameters, and operating frequencies to optimize the hardware design for the given testing requirement. To measure unknown properties, we started with rough estimates of suitable coil sizes and circuit parameters, and then simulated circuit behavior for a number of frequencica and property values. Comparison of computed tabulations with measurements at various frequencies yielded rough estimates of the range in which the actual properties lay. Interpolation between tabulated computations proved too time-consuming, so a section was added to the program to store least squares curve fits between simulated instrument responses and conductor properties and accept manually inserted instrument measurements from which actual property values are calculated. 
Simulation of Eddy-Current Instrument Response

Computations that simulated the response of the instrument were performed on a digital minicomputer. The MULTRU program accepts the following inputs:

1. coil dimensions and dc resistances,

2. passive circuit component values,

3. frequency and magnitude for each input driving voltage,

4. amplifier galns for each frequency,

5. permeability, reeistivity, and thickness values for each conducting layer,

h. values uf lift-off bctween the driver coll and conductor stack, and

7. miscellaneous control parameters indicating the numbers of values for each variable, number of conductors, etc.

Coil characteristics are measured during fabrication and maintained on a disk data file, which is accessed by the computer program. Circuit components are known and can be adjusted by insertion or replacement of packaged components. Frequencies are selected on the basis of experience and accumulated design data from earlier work. Input voltage magnitudes and amplifier gains are arbitrary and selected for convenience, for reasons discussed below. Froperty and lift-off values are chosen according to the ranges expected in the experiments; we attempt to bracket the expected value of a property with multiple input values for it.

The MULTRU program computes the following quantities, either as direct output or in intermediate sceps:

1. Inductances of the probe coils in air (i.c., away frnm ronductors and each other);

2. real and imaginary components of individual coll impedances and mutual coupling between coils for each distinguiahable combination of conductor properties and driver coil lift-off and for one selected thickness of air (gap) between the coils;

3. amplitude and phase, relative to the driver voltage, of pickup coil (or amplificr) output voltage for each case listed in (2). The basic instrument circuit is shown in Fig. 12. 

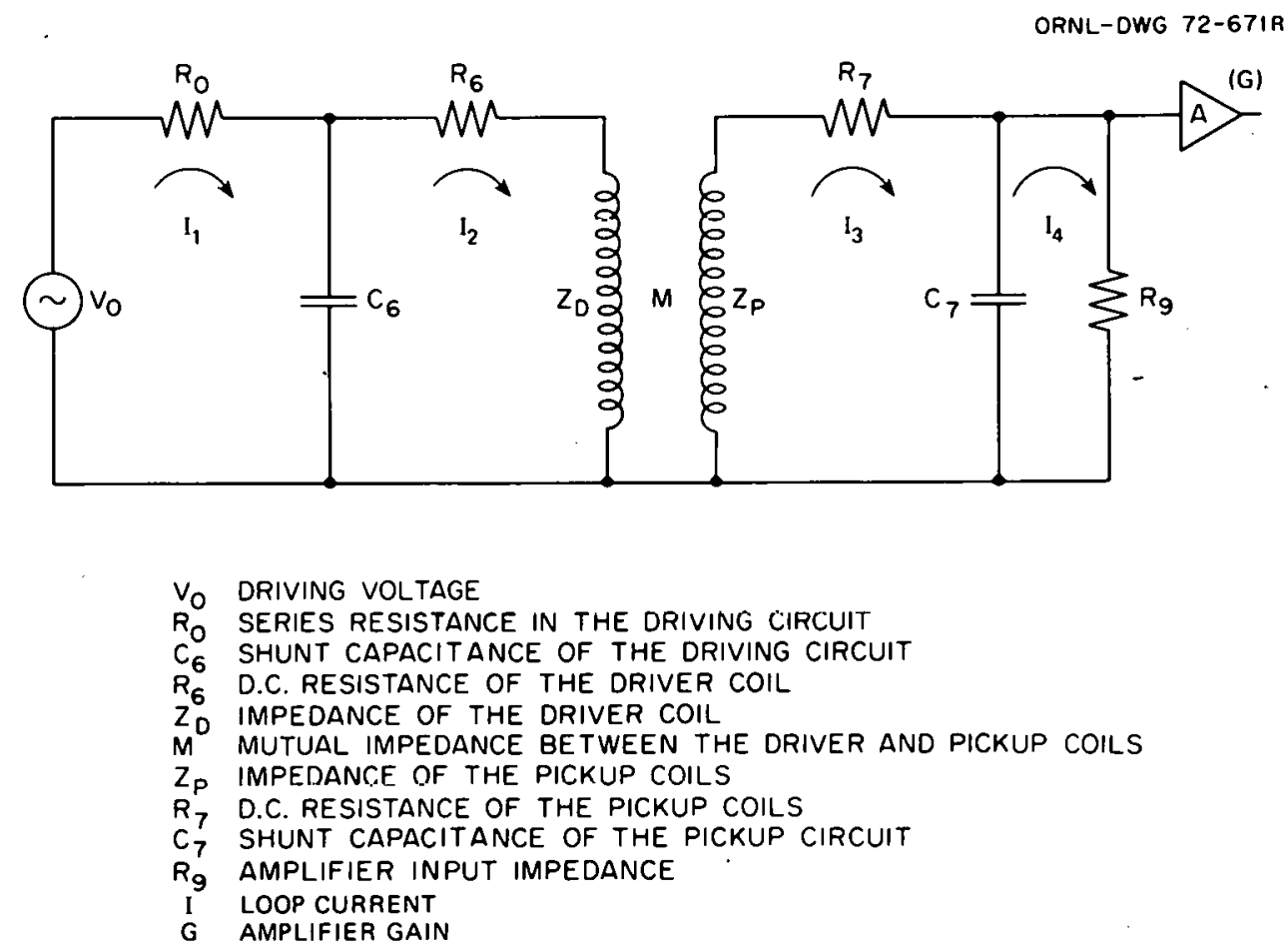

Fig. 12. Simplified Circuit Diagram for the Probe Coils and Instrument Interface in a Through-Transmission Eddy-Current System.

The program options chosen for this work adjust the response of the program in two ways. First, the spacing between the coils is adjusted to compensate for changes in conductor thickness. The results are computed as though each coll 1s always in intimate contact with its side of the conductor stack unless a fixed lift-off is specified. Secondly, the voltages and phases are normalized to the voltage and phase obtained with a specified air gap. The size of the air gap chosen corresponds to the máximum total conductor stack thickness. To normalize, each computed output voltage magnitude is divided by the air gap output voltage magnitude, and the phase of the air gap voltage is subtracted from each of the computed output voltage phases. The output thus obtained is a tabulation of normalized magnitudes and phases of the output voltage, by frequency, for each combination of conductor properties and driver coil lift-off. When normalization is used, the effects of the actual values of input voltage and amplifier gain cancel out. 
To mathematically relate conductor properties to instrument output, the program includes a least squares design section, which constructs functions of the computed readings (i.e., output voltage magnitudes and phases), compares them with a particular property, and determines the set of function coefficients that best fits the functions. Four types of reading function are selectable: linear (polynomial, integral powers), logarithm, exponential (positive exponent), and inverse (polynomial, negative integral powers); some cross terms can also be constructed. The quality of the fit can be evaluated by computing a residual sum-of-squares in the property value and by inserting known variations in the readings and computing the root-mean-square (rms) variation in the property value.

Two additional subroutines were incorporated into the original MULTRU program for use in this work. The first, called TPOLRY, stores polynomial coefficients generated by the fitting process; the second, TPRCAL, accepts manually inserted instrument readings from specimens, recovers the polynomial function coefficients, and computes selected properties from the readings.

Property values for initial insertion into the program were generated from a combination of experimental constraints and estimates. Sperimens were çonvenlently pruducible with conting thicknesses in the range 0.25 to $0.50 \mathrm{~mm}(0.010-0.020 \mathrm{ln}$.), so we included the range 0.13 to $0.64 \mathrm{~mm}(0.005-0.025 \mathrm{in.})$ in the program and used step values 0.13 , $0.30,0.46$, and $0.64 \mathrm{~mm}(0.005,0.012,0.018$, and $0.025 \mathrm{in.}$ ).

As noted earlier, the relative permeability, $\mu_{r}$ was expected to be between 1 and 60 , so calculations were done in two sets: $\mu_{p}=1,5,10$, 20 ; and $\mu_{r}=30,40,50,60$. Reslstivity values were also tinserted il two sets: $\rho=1.00,2.00,3.00,4.00 \mu \Omega \mathrm{m}$ and $\rho=5.00,6.00,7.00$, $8.00 \mu \Omega$ m.

We attempted experimental lift-off control by maintaining positive probe pressure against the specimen with holding devices. One increment of lift-off was included to allow for possible effects of specimen curvature; the values were zero and $38 \mu \mathrm{m}$ (0.0015 in.). 
Frequency selection included several considerations. First, a ratio of at least 5 between frequencies in a dual-frequency test assures useful sensitivity, and a ratio of 10 is better. Second, lower frequencies are somewhat less demanding of the instrument; phase measurements above $1 \mathrm{MHz}$ impose difficult timing requirements. Third, the initial calculations for $\mu_{r}=60$ at $500 \mathrm{kHz}$ showed phase shifts between 180 and $360^{\circ}$. If the phase shift resulting from insertion of a specimen (compared with an air gap the same thickness) exceeds $360^{\circ}$, then the phase reading becomes ambiguous, and attempts to construct function fits between instrument readings and conductor properties yield meaningless results. Since least squares fits of functions were not planned until experiment data helped to narrow the property ranges, initial calculations were done for seven frequencies on a single program run: 5, 10 , $20,50,100,200$, and $500 \mathrm{kHz}$.

We have not attempted to optimize coil sizes for throughtransmission applications, but many of the principles associated with the selection of reflection coil sizes are expected to apply. The best coils available in our inventory had $1.0-\mathrm{mm}(0.040-\mathrm{in}$.) radii, and a matched set was avallable, so calculations using their characteristics were performed.

The high-frequency noise that occurs in the pickup of reflection coil systems does not get transmitted through metallic specimens, so resonant frequencies of the coll c1rcults (Fig. 12) are not critical. The only requirement is to keep them well above the operating frequencies. The circull cumponent inputs were simplified insofar as possible. The shunt capacitances, $C_{6}$ and $C_{7}$, approximated the cable capacitances only, and no add-on components were used. We set $R_{0}$ at $2000 \Omega$ to minimize lift-off effects.

\section{Experimental Measurements}

Measurements on specimen (Fig. 4, p. 10) were made with a singlechannel phase-sensing eddy-current instrument. The probe colls were matched 40-A reflection probes, of which only the driver colls were used. The colls were supported by a $\mathrm{C}$-shaped fixture, which maintained coaxial alignment and allowed axtal motion for insertion and removal of the specimens. 
Frequencies available by selection included a 1, 2, 5 sequence from $1 \mathrm{kHz}$ to $2 \mathrm{MHz}$. The instrument reads out the absolute magnitude of the amplifier output voltage (Fig. 12) and its phase relative to that of the input voltage. The digital panel meter (DPM) indicating phase is calibrated for $0.100 \mathrm{~V} / \mathrm{deg}$; its range of $\pm 13 \mathrm{~V}$ allows display of a range of only about $260^{\circ}$, although a balance control allows this range to be set up over any interval between -360 and $+360^{\circ}$.

Experimental measurements were made at each selected frequency by the following procedure:

1. The probes were spaced to $0.64 \mathrm{~mm}(0.025 \mathrm{In}$.) by insertion of a plastic shim.

2. The phase was set by using the balance control to the value computed by the MULTRU program for a 0.64-mm (0.025-in.) air gap and recorded.

3. The magnitude of the output voltage for the air gap was measured.

4. The probes were moved apart to a point where the output vollage reached a low level and stopped decreasing with coil separation. This voltage was recorded.

5. The magnitude and phase of the output voltage were measured at four points on the coating specimen with the driver and pickup coils pressing against opposite sides of the free-standing layer.

To correct the data for comparison with computed results, the "noise" voltage magnitude (step 4 above) was subtracted from each of the $n$ ther magnitude measurements. Then the remalning specimen voltage magnitudes were each divided by the $0.64-\mathrm{mm}(0.025-\mathrm{in}$.) air gap voltage magnitude. Each of the phase measurements on the specimen was subtracted from the air-gap phase value.

\section{Property Calculations}

Preparatory to the computations from experimental measurements, the program (MULTRU) was set up for two frequencies at a time, in pairs corresponding to the experimental measurements. After the least squares 
fits were calculated, the experimental measurement values were manually inserted into the program via CRT terminal keyboard, and the resulting property values were calculated.

Independent Thickness Measurements

To provide a comparison with computed results, the thickness of the coating layer was measured with a micrometer caliper. Because of the slight bow in the coating layer the micrometer was equipped with one ball and one flat anvil; the flat anvil was placed on the convex surface of the coating.

Results

Tables 11 and 12 include samples of the results obtained. Table 11 lists the coefficients of the various terms in the functions used to

Table 11. Polynomial Functions for Least Squares Fits of Simulated Eddy-Current Instrument Readings to Specimen Properties

\begin{tabular}{|c|c|c|c|}
\hline & $\begin{array}{l}\text { Resistivity } \\
\quad(\mu \Omega \mathrm{m})\end{array}$ & $\begin{array}{c}\text { Relative } \\
\text { Permeability }\end{array}$ & $\begin{array}{l}\text { Thickness } \\
(\mathrm{mm})\end{array}$ \\
\hline $\begin{array}{l}\text { Property values used } \\
\quad \text { in fit }\end{array}$ & $7,8,9,10$ & $3,4,5,6$ & $\begin{array}{l}0.127,0.3048, \\
0.4572,0.635\end{array}$ \\
\hline $\begin{array}{l}\text { Terms of empirical } \\
\text { equation }{ }^{b}\end{array}$ & $\begin{array}{l}26.22 \\
217.2 \log M_{1} \\
17.73 P_{1} \\
-238.5 \log M_{2} \\
-0.4526 P_{2}\end{array}$ & $\begin{array}{l}-8.330 \\
-1.451 \log M_{1} \\
1.273 \exp \left(P_{1}\right) \\
1.454 \log M_{2} \\
-0.833 P_{2}\end{array}$ & $\begin{array}{l}0.7062 \\
3.851 M_{1} \\
0.03863 P_{1} \\
-4.191 M_{2} \\
2.503 \exp \left(P_{2}\right)\end{array}$ \\
\hline RMS residual & 0.543 & 0.634 & 0.0414 \\
\hline RMS $d r i f t^{c}$ & 0.227 & 0.078 & 0.00139 \\
\hline
\end{tabular}

$a_{\text {Equations were fit to computed readings for the } 64 \text { possible }}$ combinations of the resistivity, permeability, and thickness values.

$b_{M_{1}}$ output voltage, $P_{1}$ phase at $100 \mathrm{kHz} ; M_{2}, P_{2}$, at $1 \mathrm{MHz}$; all relative to values with no specimen (air gap).

${ }^{c}$ Drift is generated by sequentitally introducing a $1 \%$ change into each $M$ and a $n .01^{\circ}$ shange into each $P$ then computing the rmo difference from the corresponding function value with no drift. 
Table 12. Summary of Yeasuzements and Calculations of Property Values for Free-Standing CoCrAlY Coating Layers

\begin{tabular}{|c|c|c|c|c|c|c|c|c|}
\hline \multirow{3}{*}{$\begin{array}{l}\text { Locazion } \\
\text { on } \\
\text { Specimen }\end{array}$} & \multicolumn{4}{|c|}{ Instrument Reading $b$} & \multicolumn{3}{|c|}{ Computed Property Values ${ }^{c}$} & \multirow{3}{*}{$\begin{array}{l}\text { Measured } \\
\text { Thickness } \\
(\mathrm{mm})\end{array}$} \\
\hline & \multicolumn{2}{|c|}{$100 \mathrm{kFz}$} & \multicolumn{2}{|c|}{$1 \mathrm{MHz}$} & \multirow{2}{*}{$\begin{array}{l}\text { Resistivity } \\
\quad\left(\mu S_{0} \mathrm{~m}\right)\end{array}$} & \multirow{2}{*}{$\begin{array}{c}\text { Relative } \\
\text { Permeability }\end{array}$} & \multirow{2}{*}{$\begin{array}{l}\text { Thickness } \\
\text { (mm) }\end{array}$} & \\
\hline & $M_{1}$ & $P_{1}$ & $M_{2}$ & $P_{2}$ & & & & \\
\hline A & 0,931 & -2.02 & 0.885 & -19.88 & 12.78 & 2.68 & 0.500 & 0.439 \\
\hline B & 0.935 & -1.86 & 0.887 & -18.38 & 18.27 & -3.706 & 0.559 & 0.401 \\
\hline C & $0.89 J$ & -2.25 & 0.891 & -21.63 & -16.70 & 1.116 & 0.312 & 0.447 \\
\hline$D$ & 0.969 & -1.71 & 0.933 & -17.21 & 13.39 & 2.79 & 0.461 & 0.406 \\
\hline
\end{tabular}

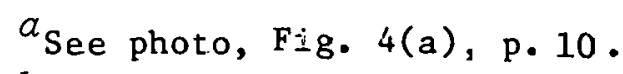

$b_{M_{1}}=$ masnitude; $P_{1}=$ phase; both readings normalized with respect to air-gap readings. $c_{\text {By }}$ using fitting functions listed in Table 11.

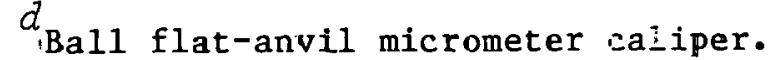


compute the property values from the instrument readings. Table 12 lists the instrument readings for each point measured on the specimen, the property values computed for those points (by using the functions listed in Table 11), and the thickness values determined from the independent micrometer measurement.

Discussion

At this stage of the work we cannot evaluate the accuracy of all the computed property values in Table 12. Clearly, the negative values for resistivity and permeability are meaningless and serve to indicate the instability of the functions used with respect to certain instrument variations. Examination of many sets of readings, without the use of fits, indicates that the resistivity falls between 7 and $9 \mu \Omega \mathrm{m}$ and the permeability falls between 3 and 5 .

The preferred method of "fine tuning" the system for this type problem includes making a set of instrument readings from known standards, for which property values are measured independently. Then the fitting functions are determined by computing fits between the known property values and the actual instrument readings. This method eliminates the effects of variations in instrument linearity and coil impedance (caused by real winding errors), which cannot be readily determined or introduced into the idealized design computations.

During the experiments we discovered a nonlinearity in the response of the 1-MHz pickup amplifier. Its effect may be reoponsible for the apparently bad property values computed from the instrument readings. The effect of this nonlinearity might have been removable by constructing the property fits from readings and data on standards.

We have not yet developed resistivity standards to fit the range of values this problem appears to require. Permeability standards represent another prohlem, since their independent mcaourcment can be quite difficult. However, if enough different values of permeability are present in standards, together with known variations in thickness and resistivity, the fits developed for thickness may discriminate against 
the permeability variations. This technique may be extendable to the reflection coil design also. Tests in the through-transmission mode should be conducted first to establish the discriminatory capability.

\section{Conclusions}

The work under way and described above was halted by termination of the project. The absolute measurement of resistivity and permeability by through-transmission eddy-current methods appears feasible, although it has not been conclusively demonstrated. Results obtained thus far indicate that computer-alded design of a mulctfrequency eddy-curreul test for the thickness of ferromagnetic coatings is also possible.

\section{THERMAL-INSPEC'IION METHODS \\ W. A. Simpson, Jr.}

Thermal inspection problems and methods were discussed in an earlier report; ${ }^{1}$ part of that discussion is included here for completeness.

Thermal inspection methods are based on local variations in the rate of heat transfer through a workpiece. These variations are detected by measuring temperatures on the workpiece surface. A passive workpiece is interrogated by the injection or removal of heat across some portion of its surface. Thermometric methods measure instantaneous temperatures at points, simultaneously or in a sequential or scanning mode. Thermographic methods generate an instantaneous image of a finite area on the workpiece surface and depict temperature as some property of the image, such as brightness, color or isothermal contours. Scanning thermometric methods with continuous recording can also generate images that represent the entire part. Either method may use contacting or noncontacting detectors.

Thermal methods have enjoyed their greatest application to inspection of layered, bonded, or coated structures. They are most sensitive to lamellar defects, which interrupt heat transmission over a finite 
area. Structures containing nonmetallic layers are sometimes easier to inspect because heat transmission is less rapid and thermal "images" of defects persist longer.

Early inspection equipment and procedures were developed experimentally. Experiments are still required, but they can be assisted by computational techniques. Rapid computation of solutions to heat flow problems can simulate some experiments and screen out unnecessary ones.

\section{Theory}

Transient solutions to one- or two-dimensional heat flow equations can be combined to construct the response of a coating-substrate system to a rapid-scanning or pused heat source. Any form of thermal excitation can be decomposed into thermal wave components by Fourier transformation. Each wave component obeys a dispersion law of the form

$$
i \omega=k k^{2} \text {, }
$$

where

$$
\begin{aligned}
& \omega=\text { the temperature oscillation frequency, } \\
& \kappa=\text { thermal diffusivity, and } \\
& k=\text { the complex wave number. }
\end{aligned}
$$

Equation (1) leads to a phase velocity

$$
v_{p}=(2 \kappa \omega)^{1 / 2}
$$

which depends on the frequency, and its corresponding wavelength,

$$
\lambda=2 \pi(2 \kappa / \omega)^{1 / 2}
$$

The form of Eqs. (1) and (2) assures that any pulsed heat input will change its pulse shape rapidly and may not be detectable as a pulse with equipment based on current technology.

To detect a defect by scattered heat, the incident wavelength [Eq. (3)] should be of the order of the defect size or smaller. The maximum 
thermal contrast at the surface of a coating layer from a defect at the coating-substrate interface will follow the heat pulse by about the time required for a wave of the corresponding frequency to make a round trip through the coating layer.

Alternatively, one can separate a scanning heat source and detector to establish quasi-steady-state heat flow conditions. When a source of appropriate size is passed over a coating layer structure at the appropriate speed, the temperature sensor will reach the point on the surface above a flaw at the instant when the transient caused by the flaw produces the maximum temperature difference. Defects will be detected by the difference between the temperatures measured over a defect and over a sound structure.

Scanning inspection devices use a heat source followed by one or more thermometric detectors. By using two sequential temperature measurements following heating, one can correct for emissivity variations of the workpiece surface. 33 Typical heat sources are plasma torches, hot gas jets, and eddy-current induction heaters. Radiometers and low-mass (i.e., low thermal inertia) thermistors are used for detection. Continuous processing and recording, synchronized with the scanner motion, can produce a plan-view record of the quasi-steady-state condition at all points in the scan pattern.

\section{Experimental Work}

We designed a thermistor probe for testing coated samples. An earlier design, which was developed for a problem in tubing similar to the present studies in coatings, is shown in Fig. 13. Although inductive heating is depicted, other forms of heating, such as hot gas and radiant energy, may be used. However, the inductive approach is generally preferred since it is easy to apply, easily controlled, and independent of surface emissivity.

In operation, the probe scans along the surface of the sample. The rate of scanning is adjusted to provide the optimum heat input, as determined by computer calculation and experimentation, and depends upon the degree of inductive coupling between the coil and the sample, electrical conductivity of the sample, etc. The distance between the 


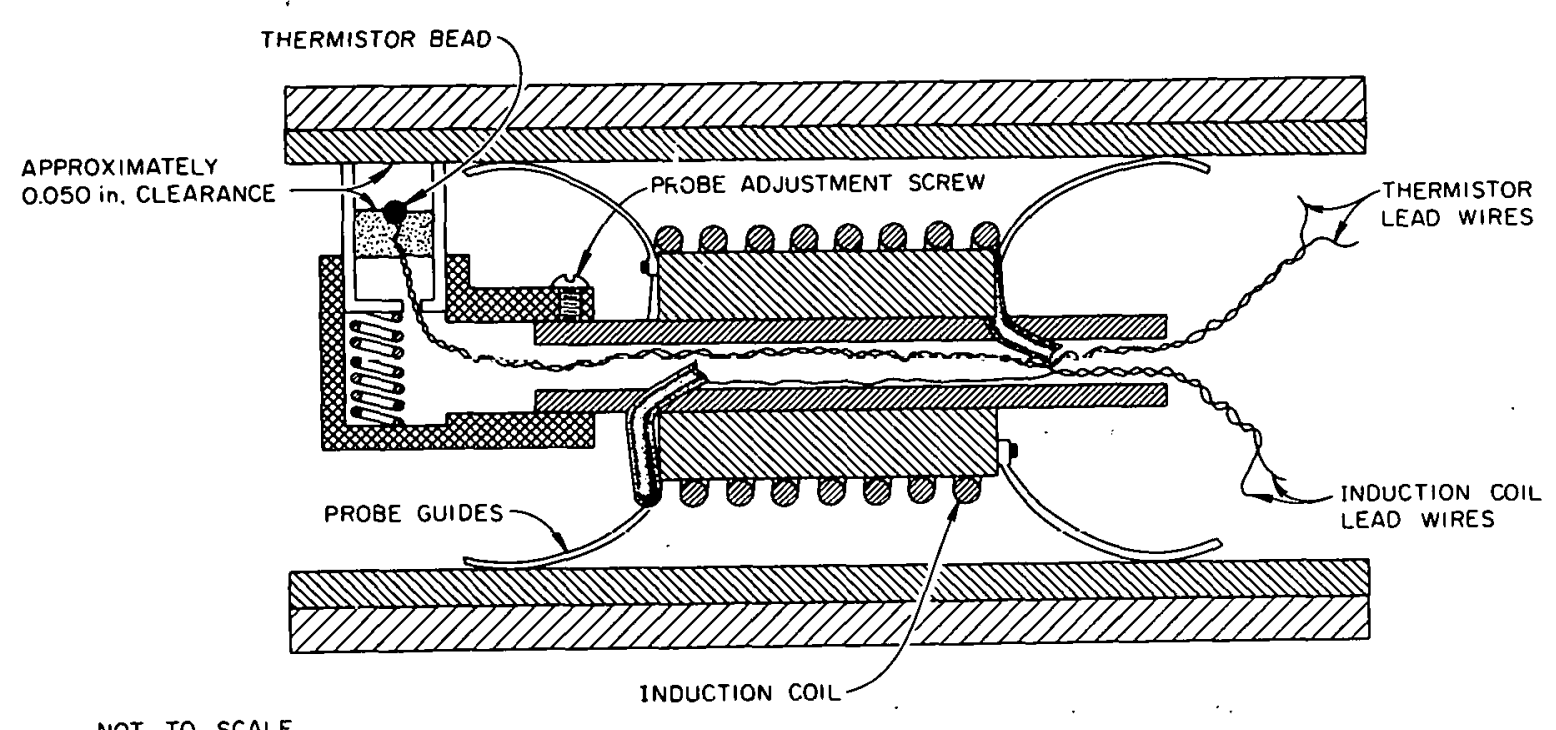

NOT TO SCALE

Fig. 13. A Representative Design of a Thermal Probe for Tubing Inspection. Clearance shown is about $1.3 \mathrm{~mm}$.

thermistor sensor and the center of the induction coil is also adjustable to allow positioning the sensor to sample the surface temperature distribution at the optimum time following heat injection; this adjustment is also determined by computer calculation and experimentation. The close proximity of the sensor to the sample surface ensures that the thermistor can follow the temperature variations encountered while avoiding damage by contact with the rough surface.

Figure 14 shows the design of the coating probe. The thermistor sensor is a special low-mass device having a time constant of approximately $0.1 \mathrm{~s}$. This response should suffice for all anticipated test conditions. The ball-bearing face plate was chosen for the probe to minimize wear and allow the probe to move easily over rough surfaces. As the drawing illustrates, the sensor itself does not contact the test surface but rides approximately $1.3 \mathrm{~mm}$ ( $0.05 \mathrm{in.})$ above the surface. The small size of the gap ensures that the response time of the system is not seriously impaired. Furthermore, the gap itself protects the thermistor. 


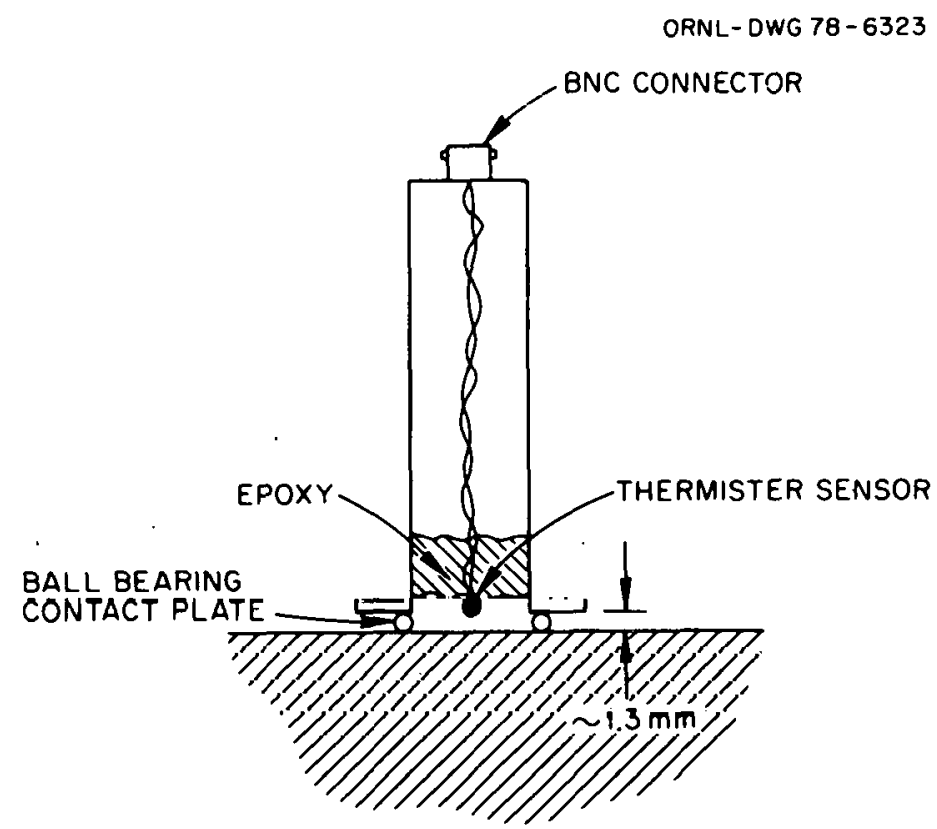

Fig. 14. Cross Section Showing Thermal Coating Probe Design.

Because the thermistor is extremely sma11 - $0.13 \mathrm{~mm}$ in diameter, with a wire size of approximately $15 \mathrm{um}$ - the final assembly of the probe was contracted to an outside firm that specializes in fabricating miniature electrical probes.

To convert the resistance variations of the thermistor into a usuable measure of temperature variation, a bridge-type detector was designed for the system and 1s shown in FIg. 15. The ourpur of the bridge is amplified by an operational amplifier and then displayed on a chart recorder. The electronics must be capable of operating down to dc

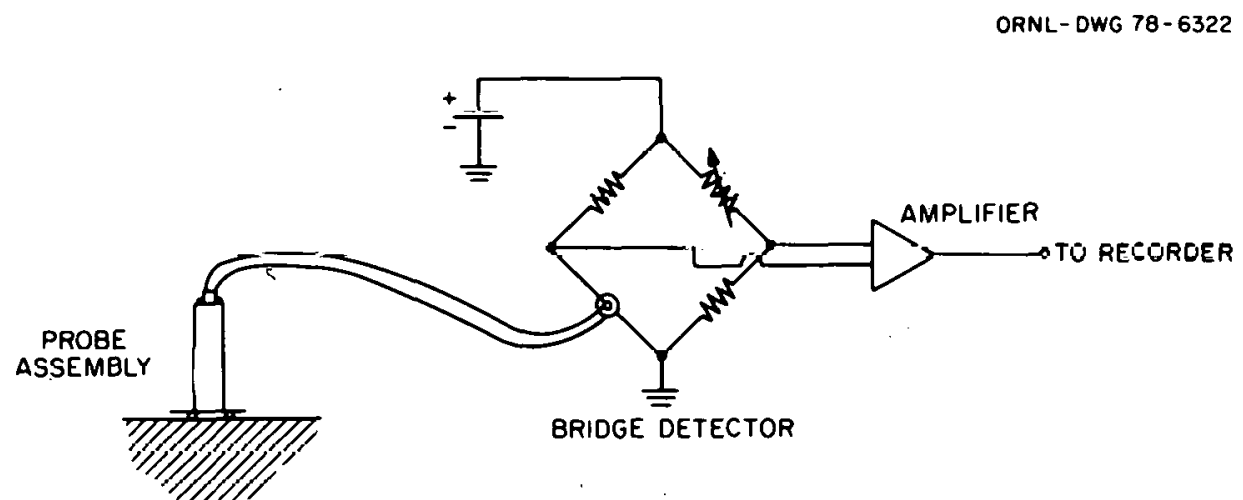

Fig. 15. Schematic of Bridge Detector for Thermal Probe. 
in frequency, but the gain is not critical. If desired, an $x-\dot{y}$ recorder could be substituted for the chart recorder and the sweep voltages. derived from the probe scan mechanism. This would produce a 1:1 mapping of the scanned area onto the chart. A voltage comparator could then be added to the pen-lift circuit of the recorder so that the temperature variations that exceeded a selected value would record, thus producing a plan-view recording of the temperature distribution on the sample surface. This is a preliminary design, and the final configuration would be determined by experimentation with the assembled probe.

Unfortunately, the project was terminated shortly after receipt of the probe from the assembler and the planned experiments with it were not carried out.

\section{Conclusions}

No experiments were performed, so no firm conclusions about the capabilities or limitations of thermal coating inspection can be stated. Our speculation, based on earlier experiments with materials other than metallic coatings, is that thermal coating inspection is feasible.

\section{CURRENTLY AVAILABLE INSPECTION TECHNOLOGY:} SUMMARY AND ASSESSMENT

Our evaluation of the current state of the art in inspection of plasma-sprayed metallic coatings is summarized below. Appropriate limitations or restrictionis are noted.

\section{Limitation of Reported Work}

Experimental work described herein did not, in general, reach the stage at which absolute limits or sensitivity, resolution, etc. could be determined or measured. Therefore, estimates of these quantities are not included. 
Most of the work described here was conducted with a single material, which has some properties characteristic of other CoCrAlY or MCrAlY coatings and of metallic plasma-sprayed coatings in general. Therefore some conclusions may be reached with respect to those common properties, but some specifics may not be available.

The specimens used were made under what amounts to laboratory conditions. Additional variability and sources of variability may appear in coatings applied under industrial environmental conditions.

Crack and Hole Detection

Liquid penetrant testing (PT) comes closest to providing an offthe-shelf method, although modifications to conventional techniques have been demonstrated as necessary. The exact lower (crack size) limit of sensitivity was not determined, but it appears to approach that of more conventional PT techniques. There is also some potential for technique variation to classify cracking by size range.

Radiography was not completely investigated under controlled laboratory conditions but demonstrated a useful practical capability for checking the condition of specimens known to have cracks. Some additional work would establish the sensitivity of techniques with the coating placed film side. Double-wall or source-side techniques may be worth investigating.

Eddy-current techniques were not developed to the point of demonstrating flaw detection capability, but past experience indicates strong potential for success without excessive development effort. Much of the development required for crack and hole detection would parallel that required for thickness measurement.

\section{Thickness Measurement}

Eddy-current techniques appear to offer the quickest and most positive method to satisfy this requirement. Because of the ferromagnetic properties of the CoCrAlY coating materrial used here and the liklihood 
of similar properties in other candidate materials, some additonal effort to develop methods to handle these materials would be a good investment. It appears that the more modern multifrequency eddy-current techniques will be required.

$\dot{X}$-ray fluorescence (XRF) techniques are near their upper limit of useful sensitivity at a coating thickness of $0.25 \mathrm{~mm}(0.010 \mathrm{in}$.), when that coating contains low- to medium 2 (atomic number) elements. For higher $Z$ elements, the limiting thickness for XRF measurement could be much smaller. The method could be very useful for low- to medium-Z coatings less than $0.25 \mathrm{~mm}$ ( $0.010 \mathrm{in.})$ thick, particularly if such coatings were deposited on higher $Z$ substrates.

U1trasonics has not been effectively investigated for this application. Coating porosity can be expected to introduce some unusual acoustic properties into the measurement problem. Significant development effort is likely to be required.

\section{Detection of Unbond Areas and Delaminations}

In general, definitive experiments were not performed in this area. Earlier results on metallic coatings with ultrasonics ${ }^{34}$ indicate good potential for the detection of missing or unbonded coating areas. The assumption here is that the acoustic properties of metallic plasmasprayed coatings will be close to those of nonmetallic coatings already examined.

3canning chermometric techniques were brought to the point at which useful experiments could have been performed. Here, also, earlier work provides an indication of potential applicability. 35 In this case, however, a significant difference in thermal properties is likely. The diffusion mechanisms involved in image formation will be accelerated, and the increase in speed will have to be compensated for by modificaLions to equipment or the technique.

Electric current testing was not experimentally examined at all, mainly because of its initial priority assignment and the late arrival of equipment for it. 
Conclusions and Recommendations

Inspection techniques for cracks and holes open to the coating surface have come closest to complete development. Some further development of radiography would be profitable. Thickness measurement by eddy-current techniques is closest to useful development and should be completed. Ultrasonic and thermal unbond detection methods should have about equal attention. The remaining methods should be considered only if significant resources for development become available.

\section{ACKNUWLEDGMENTS}

J. D. Hudson and D. P. Edmonds developed in-house spray process equipment and spraying techniques to manufacture the specimens used in this work. H. T. Murrin and T. Underwood performed special machining operations on sprayed specimens and made prototype blanks. W. J. Mason performed the radiography documented herein. R. T. King provided steadfast program management, helping to maintain an in-house goal framework. J. H. Smith and G. M. Goodwin reviewed the report, S. Peterson edited It, and K. A. Witherspoon of the Metals and Ceramics Division Reports office prepared the reproducible copy.

\section{REFERENCES}

1. G. W. Scott, K. V. Cook, E. V. Davis, C. F. Dodd, B. E. Foster, W. J. Mason, R. W. McClung, W. A. Simpson, Jr., and S. D. Synder, Nondestructive Inspection of Thin Plasma-Sprayed Ceramic and Cermet Protective Coatings for Coal Conversion and Utilization Equipment, ORNL/TM-6210 (Apr11 1978).

2. R. Swaroop, Materials Science Division Coal Technology Fourth Quarterly Report, July-September 1975, ANL-76-7, Task B.

3. Ibld. Fifth Quarterly Report, Octobem-December 1975, ANL-76-22, Task B.

4. Ibid, Sixth Quarterly Report, January-March 1976, ANL-76-60, Task B. 
5. D. Stahl, Materials Science Division Coal Technology Seventh Quarterly Report, April-June 1976, ANL-76-111, Task B.

6. S. J. Dapkunas, DOE, Washington, private communication, Aug. 30, 1977.

7. Reference 1, pp. 26-28.

8. Reference 1, pp. 28-32.

9. J. R. Alberger, Nondestructive Evaluation of Surface Microstructure Using High-Performance FZuorescent Penetrants, Section P-020.22, Bul1. 751010, Shannon-Glow, Inc., Los Angeles, California; presented to Spring Conference of the American Society for Nondestructive Testing, March 1975.

10. R. C. McMaster, Nondestructive Testing Handbook, The Ronald Press Company, New. York, pp. 15-35.

11. R. D. Evans, The Atomic Nucleus, McGraw-Hi11, New York, 1955, pp. $712-14$.

12. R. Halmshaw, "Radiographic Definition," Chap. 8 in Physics of Industrial Radiology, Heywood Books (Iliffe, Ltd.), London, 1966 (American Elsevier, New York), p. 180.

13. "Standard Recommended Practice for Radiographic Testing," ASTM -E 94-77; 1978 Annual Book of ASTM Standards, Part 11: Metallography; Nondestructive Tests, American Society for Testing and Materials, Philadelphia.

14. H, A. Klasens, "Measurement and Calculation of Unsharpness Combinations in X-ray Photography," Phillips Research Reports 1(4): 24149 (1946).

15. "Standard Method for Controlling Quality of Radiographic Test," ASTM E 142-77; 1978 Annual Book of ASTM Standards, Part 11: Metallography; Nondestructive Tests, American Society for Testing and Materials, Philadelphia, Appendix Al.4, p. 258.

16. B. E. Foster, E. V. Dav1s, and R. W. McClung, High-Resolution Boreside Radiography of Small-Diameter Tube-to-Tubesheet Weld6, ORNL-5474 (February 1979).

17. Reference 15, Appendix A2, p. 259. 
18. J. Sherman, "The Theoretical Derivation of Fluorescent X-Ray Intensities from Mixtures," Spectrochem. Acta 7: 283 (1955).

19. H. J. Lucas-T'ooth and B. J. Price, "A Mathematical Method for the Investigation of Inter-Element Effects in X-Ray Fluorescent Analysis," Metallurgia 64: 149-52 (1961).

20. L. S. Birks, X-Ray Spectrochemical Analysi.s, Interscience, New York, 1959.

21. C. V. Dodd, "Applications of a Phase-Sensitive Eddy-Current Instrument," Mater. Eval. 22(6): 260-63 (June 1964).

22. C. V. Dodd, "A Portable Phase-Sensitive Eddy-Current Instrument," Muler. Evai. 26(3): 33-36 (March 1968).

23. C. V. Dodd and W. A. Simpson, Jr., Thickness Measurements Using Eddy Current Techniques, ORNL/TM-3712 (March 1972).

24. J. T. Hill, Clad Thickness Measurement Using Dual Frequency Eddy Current, Y-1970 (May 1975).

25. C. V. Dodd, C. C. Cheng, J. H. Smith, and W. A. Simpson, The Analysis of Reflection Type Coils for Eddy-Current. Testing, ORNL/TM-4107 (Apri1 1973).

26. Reference Data for Radio Enqineers, 5th ed., H. W. Sams and Co., Inc., Indianapolis, 1968.

27. C., V. Dudd aud W. A. Simpson, "Mcaeurement of Sma1,1 Magnetic Permeability Changes by Eddy-Current Techniques," Mater.

Evar. 29(10): 217-21 (October 1971).

28. C. V. Dodd and C. C. Lu, "Nondestructive Test for Measuring the State of Heat Treatment in Closure Welds," Mater. t'val. 30(7): 142-48 (July 1972).

29. J. H. Smith, An Evaluation of the Use of Eday Currenls lo Mearume tho Thiaknoes of Ni.eke?. P1.ntting m Carbon Steel, K-1845 (Oct. 17, $1973)$.

30. W. E. Deeds, C. V. Dodd, and G. W. Scott, Computer-Aided Design of Multifrequency Eddy-Current Tests for Layered Conductore with Mutliple Property Variations, ORNL/TM-6858 (October 1979).

31. C. V. Dodd, Basic Principles of Eddy Current Testing, report in preparation. 
32. 1975 Annual Book of ASTM Standards, Part 44, Magnetic Properties; Metallic Materials for Thermostats and for Electrical Resistance, Heating, and Contacts; Temperature Measurement, American Society for Testing and Materials, Philadelphia, pp. 1-179.

33. D. R. Green, "Principles and Applications of Emittance-Independent Infrared Nondestructive Testing," Appl. Opt. 7(9): 1779-89 (September 1968).

34. Reference 1, pp. 70-72.

35. Reference 1, pp. $61-66$. 


\section{THIS PAGE \\ WAS INTENTIONALLY \\ LEFT BLANK}


ORNL/TM-7090

Distribution

Categories UC-90c, $-\mathrm{h}$

\section{INTERNAL DISTRIBUTION}
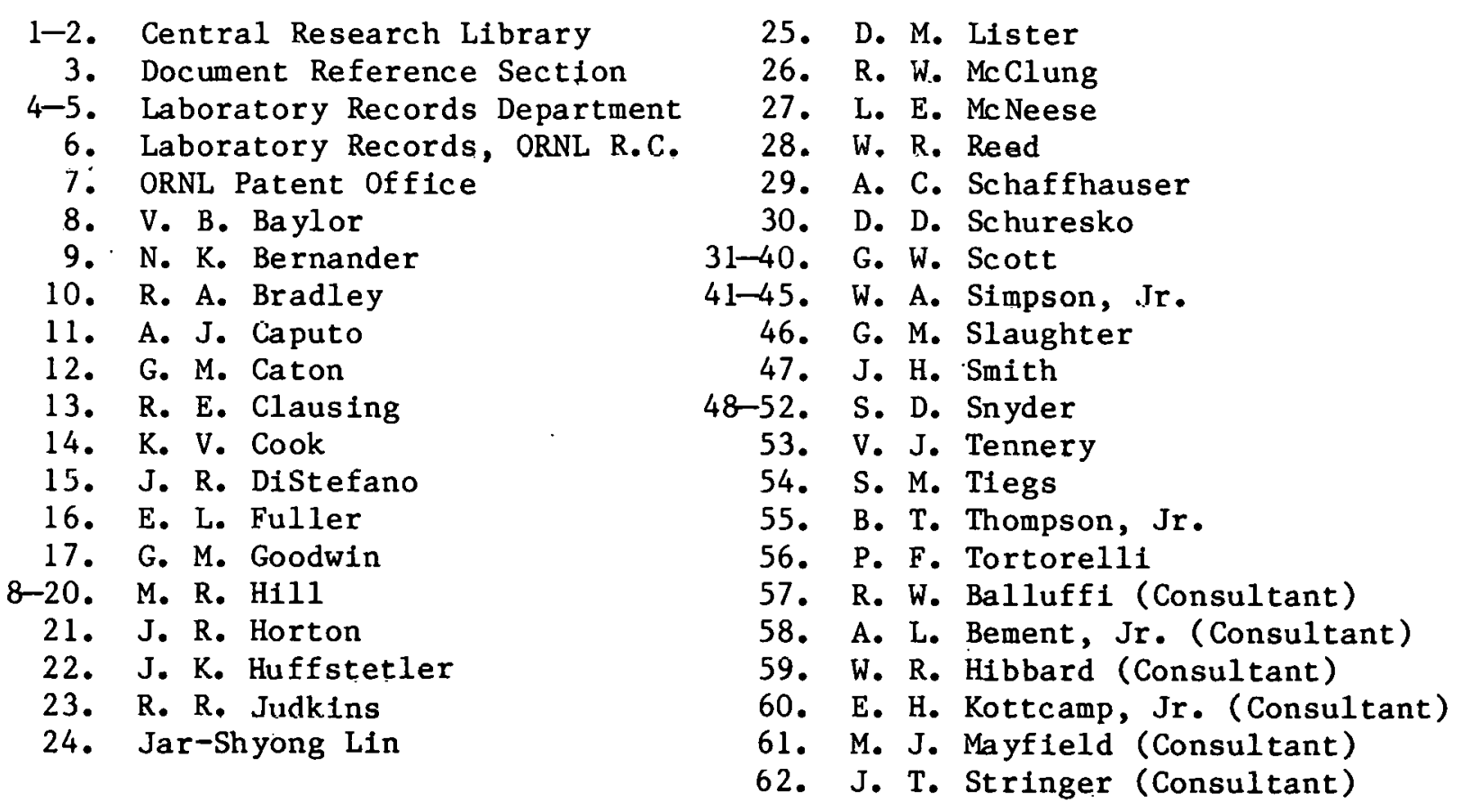

EXTERNAL DISTRIBUTION

63-64. IUWA STATE UNIVERSITY, Ames, IA 50011

T. E. Scott, Ames Laboratory, 126 Metals Development Bldg.

J. R. Smith, 110 Euylneer1ng Annex

65. SPRAGUE ELECTRIC COMPANY, Marsha1. Street, North Adams, MA 01247

R. T. King

66-68. DOE OFFICE OF FOSSIL ENERGY, 20 Massachusetts Avenue, N.W., Washington, DC 20545

S. J. Dapkunus

John Fairbanks

H. E. Frankel

69. DOE OAK RIDGE OPERATIONS OFFICE, P.O. Box B, Oak Ridge, TN 37830

Assistant Manager, Energy Research and Development

70-338. DOE TECHNICAL INFORMATION CENTER, Office of Information Services, P.0. Box 62, Oak Ridge, TN 37830

For distribution as shown in TID-4500 Distribution Category, UC-90c (Coal Gasification) and UC-90h (Materials and Components). 